\title{
Evaluating the Corresponding Relationship Between the Characteristics of Resource Utilization and the Level of Urbanization囚A Case Study in Chengdu- Chongqing Economic Circle, China.
}

\section{Ying Zhou}

Sichuan Agricultural University

Zhuolu Li

Sichuan Agricultural University

\section{Yuan Chen}

Sichuan Agricultural University

Wei Wei ( $\nabla$ jpwflz@sicau.edu.cn )

Sichuan Agricultural University https://orcid.org/0000-0003-4984-6464

\section{Research Article}

Keywords: Urbanization, Natural resources, PSR, Piecewise regression analysis, Moran Index, ChengduChongqing Economic Circle

Posted Date: September 24th, 2021

DOI: https://doi.org/10.21203/rs.3.rs-692395/v1

License: (c) (1) This work is licensed under a Creative Commons Attribution 4.0 International License.

Read Full License 


\section{Evaluating the corresponding relationship between the}

2 characteristics of resource utilization and the level of

3 urbanization: a case study in Chengdu-Chongqing Economic

4 Circle, China.

Ying Zhou ${ }^{1}$, Zhuolu Li ${ }^{1}$, Yuan Chen ${ }^{1}$, Wei Wei ${ }^{1 *}$

1 School of Architecture and Urban Planning, Sichuan Agricultural University, Sichuan 611830, China; E-Mails: zhouying3333@163.com (Y.Z.); nyanya000@163.com(L.Z.L.); cyuanyuaner@163.com (Y.C.); jpwflz@sicau.edu.cn (W.W.).

* Address of Corresponding Author: School of Architecture and Urban Planning, Sichuan Agricultural University, Sichuan 611830, China; E-Mail: jpwflz@ sicau.edu.cn; Tel.: +8615982343612 .

\section{Declarations}

"I have not submitted my manuscript to a preprint server before submitting it to Environmental Science and Pollution Research".

Ethics approval and consent to participate: Not applicable.

Consent for publication: Not applicable.

Availability of data and materials: The "Resource consumption and urbanization level" data that support the findings of this study are mainly available from "Sichuan Statistical Yearbook 2016", (http://tjj.sc.gov.cn/tjnj/cs/2016/indexch.htm) and "Chongqing Statistical Yearbook 2016" (http://tjj.cq.gov.cn/zwgk_233/tjnj/2016/indexch.htm). The rest of the data comes from the public yearbooks of cities in the study area.

Competing interests: The authors declare no conflict of interest.

Funding: This paper was supported by the Tuojiang Basin High Quality Development Research Center (TJGZL2019-14), Sichuan Circular Economy Research Center (XHJJ-1906) and Research Center of Sichuan County Economy Development (XY2021008).

Authors' contributions: Writing, checking and correcting: Ying Zhou. Collect data and analyze: Zhuolu Li, Yuan Chen. Literature review and contact editor: Wei Wei.

Acknowledgements: Thanks to Dr. Zhou for her valuable advice, and the help of classmates. 
The Chengdu-Chongqing Economic Circle is an important center for promoting economic growth in the western region. Clarifying the driving force and restrictive factors of the urbanization development in Chengdu-Chongqing area is conducive to the further development of the region. First, this study uses piecewise linear regression to determine the characteristics of resource consumption. Then use Moran index to test the spatial agglomeration relationship. Finally, combining the characteristics of resource utilization and spatial agglomeration effects in Chengdu-Chongqing area, 143 cities are classified. The results show that: (1) The Chengdu-Chongqing economic circle as a whole presents the characteristics of high resource utilization pressure and abundant resource content. (2) In areas with obvious agglomeration effects, most cities have less pressure on natural resources, lower resource levels, less investment in environmental protection, and higher levels of urbanization. (3) The pressure on the use of natural resources and the expropriation of environmental protection measures are matched with each other in areas with significant concentration. (4) With the development of cities, the characteristics of resource utilization in various regions will tend to be unified. Researching and exploring the characteristics of resource utilization in the Chengdu-Chongqing Economic Circle will help the government to formulate relevant policies to ensure the coordinated development of regional ecology and the city.

Keywords: Urbanization. Natural resources. PSR. Piecewise regression analysis. Moran Index. Chengdu-Chongqing Economic Circle

\section{Introduction}

Rapid urbanization is an important trend of current world development. The main features are economic development, population migration, urban spatial expansion,etc.(C. Li, Li, \& Wu, 2013) At present, the more developed areas such as North America and Europe have a relatively high degree of urbanization, and the underdeveloped regions will become the main driving force for the growth of world cities (Madlener \& Sunak, 2011). Today, more than 50\% of the world's population lives in urban areas. According to United Nations projections, by 2050, the global population will increase to 9.3 billion. Among them, the urban population will increase to 6.25 billion, and $75 \%$ of the world's population will live in cities and their surrounding areas. In addition, $83 \%$ of the world's urban population will live in 
underdeveloped areas(UN, 2012).

The rapid development of urbanization also consumes a lot of natural resources. There is constant interaction between people and the land, and the land changes from a natural state to a state used by humans (Yansui Liu, 2018). At the same time, the concentrated use of water resources has also led to an increase in water pressure. This promotes climate and environmental changes(R. I. McDonald et al., 2011; Robert I. McDonald et al., 2014). Cities occupy only $2 \%$ of the world's area, but consume $75 \%$ of the world's resources and are accompanied by a large amount of emissions. The International Energy Agency predicts that by 2030 , the proportion of urban energy demand will increase to $73 \%$ and carbon dioxide emissions will increase to $76 \%$ (IEA, 2008). Moreover, comparing large cities in developed and developing countries, excluding traditional energy consumption, it can be found that the per capita energy consumption in developing countries is lower than that in developed countries.(Madlener \& Sunak, 2011) Therefore, analyzing the consumption of urban natural resources can also judge the urbanization process. Natural resources and urban development influence each other. The ecological environment is the external condition of urban development and the foundation of sustainable urban development.(T. Peng \& Deng, 2021). Natural resources such as water resources, forests, land, and minerals are all necessary conditions for development(Nathaniel, Nwulu, \& Bekun, 2021). But the rapid urbanization process will also cause problems such as resource degradation and environmental pollution.

According to the "China Statistical Yearbook", from 2000 to 2018, China's urbanization level rose from $36.22 \%$ to $59.58 \%$, which shows the rapid development of Chinese cities. As the fourth largest urban agglomeration in China, the Chengdu-Chongqing urban agglomeration has experienced rapid urbanization in the past few decades. From 2001 to 2015, the urbanization level of Sichuan Province rose from $26.70 \%$ to $52.3 \%$, and the urbanization level of Chongqing City rose from $35.6 \%$ to $65.6 \%$. In recent years, the rapid development of Chengdu-Chongqing area has attracted a large amount of resources inflow. The GDP of Sichuan Province and Chongqing City increased from 617.153 billion yuan to 457.037 billion yuan, and the built-up area increased from 1421.67 square kilometers to 3611.1 square kilometers. As shown in Figure 1, the overall economy of Chengdu-Chongqing area has doubled, and the city has expanded significantly. The other three urban agglomerations that were identified earlier and developed rapidly are the Yangtze River Delta, the Greater Bay Area, and the Beijing-Tianjin Wing. In 2020, the Chengdu-Chongqing urban agglomeration determined by the "Outline of the Construction Planning for the Chengdu-Chongqing Twin City Economic Circle" is located inland and has important research value.. 


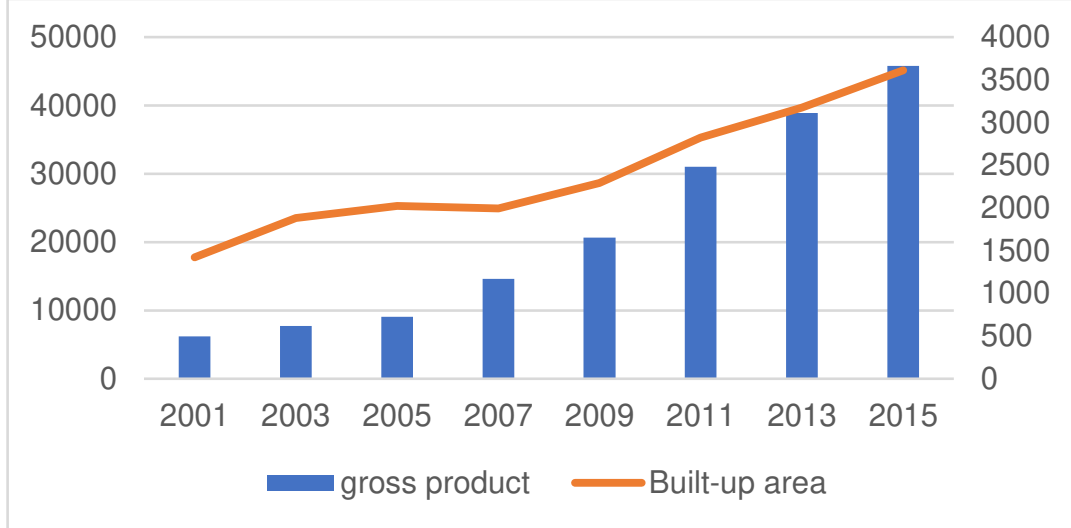

Fig.1 Changes in GDP and built-up area of Sichuan Province and Chongqing City from 2001 to 2015

There have been studies that have proved that there is a non-linear relationship between natural resource development and urbanization development (Yaobin Liu, 2014; J. Peng et al., 2017). However, due to the acceleration of industrialization and rapid economic development, environmental pollution and ecological destruction are inevitable problems in the development process. At this time, the degree of urbanization and the amount of resource possession will affect the way of resource development. For example, areas with low levels of urbanization are mostly areas with low resource development efficiency, which will cause more environmental problems. The development of resource-rich areas is too dependent on the environment, which can easily lead to industrial imbalances and affect energy conservation, emission reduction and environmental protection.(Ahmed, Asghar, Malik, \& Nawaz, 2020; He et al., 2021; K. Wang et al., 2019). There have been many studies using piecewise linear regression to identify the threshold of ecosystem changes, such as testing the threshold of habitat changes(Francesco Ficetola \& Deno $\tilde{«}$ l, 2009; Garabedian, Moorman, Nils Peterson, \& Kilgo, 2017), the threshold of socioeconomic impact on urban landscape(W. Liu, Holst, \& Yu, 2014), the ecosystem response to urbanization Threshold(Haase, Frantzeskaki, \& Elmqvist, 2014).

In addition, the relationship between environmental change and urbanization also has different temporal and spatial characteristics. Most of these studies pay more attention to the changes in urban temporal and spatial patterns. By exploring the characteristics of urbanization development (Yaobin Liu, 2014) studying changes in natural resources over the past few decades (Topcu, Altinoz, \& Aslan, 2020), distinguish urban ecological landscapes (C. Li et al., 2013; Jian Peng, Shen, Wu, Liu, \& Wang, 2015), changes in natural resources (J. Li, Li, Zhu, Song, \& Wu, 2013; Shahbaz, Loganathan, Muzaffar, Ahmed, \& Ali Jabran, 2016) (Y. Li, Cao, Long, Liu, \& Li, 2017) or predict future development (Fang et al., 2019). In terms of space, it mainly includes the spatial dynamic response of natural resource production to the 
urbanization process(R. I. McDonald et al., 2011), urbanization and environmental resource utilization(Ding \& Peng, 2018)、 the evaluation of the spatial relationship of environmental carrying capacity(K. Li, Jin, Ma, \& Jiang, 2019), urban sprawl methods, and the visualization research of urban agglomeration effects(Ramachandra, Bharath, \& Sowmyashree, 2015), etc.

As far as research purposes are concerned, most of the current research is to assess the current changes in the natural environment, or the impact of changes in the natural environment on urbanization. There are few studies on the relationship between the process of urbanization and the change of resources and environment, which is of great significance to the study of the development of the ChengduChongqing economic circle. Therefore, the main purpose of this research lies in three points: (1) Determine the response relationship between comprehensive utilization of resources and urban development; (2) Determine the spatial agglomeration effect of the Chengdu-Chongqing area; (3) Exploring the balance between resource utilization and urbanization level in Chengdu-Chongqing region will help each region integrate its own characteristics to improve development strategies. The second part of this article introduces basic data, data processing methods and models. The third part is the analysis result of the model. The fourth part discusses and analyzes the results. The fifth part is a summary. References and appendices at the end of the article.

\section{Methods}

\section{Study area and data sources}

According to the "Urban Group Development Plan" issued by the National Development and Reform Commission, the subjects of this survey have been determined. It has jurisdiction over 142 districts, including 113 cities in Sichuan Province and 29 cities in Chongqing. The Chengdu-Chongqing urban agglomeration has a vast area, with a total area of 185,000 square kilometers. Its geographic location is between $101^{\circ} 55^{\prime}-109^{\circ} 14^{\prime} 51^{\prime \prime}$ east longitude and $27^{\circ} 39^{\prime}-32^{\circ} 19^{\prime} 18^{\prime \prime}$ north latitude. It is located in the Sichuan Basin east of the Yangtze River in China. There are many mountains and rivers in Chengdu-Chongqing area, the terrain is undulating, and the water resources and forest resources are abundant. The Chengdu-Chongqing area has a subtropical humid monsoon climate, with annual precipitation of $1107.8 \mathrm{~mm}$ and $1406.4 \mathrm{~mm}$ respectively. The annual average temperature is 16.4 and 19.2 degrees Celsius respectively. It has a long history and rich natural and cultural landscape.

The data used in this article includes statistical data and spatial data. Statistical data mainly come 
from "Sichuan Statistical Yearbook 2016", "Chongqing Statistical Yearbook 2016", "Water Resources Bulletin", "Sichuan Environmental Resources Bulletin", "Chongqing Environmental Resources Bulletin", yearbooks and environmental bulletins corresponding to cities in the Chengdu-Chongqing Economic Circle. The missing data is supplemented by data from adjacent years, interpolation method, or distribution according to the total amount. Geospatial data comes from China Environmental Resources Science and Data Center (https://www.resdc.cn/Default.aspx).

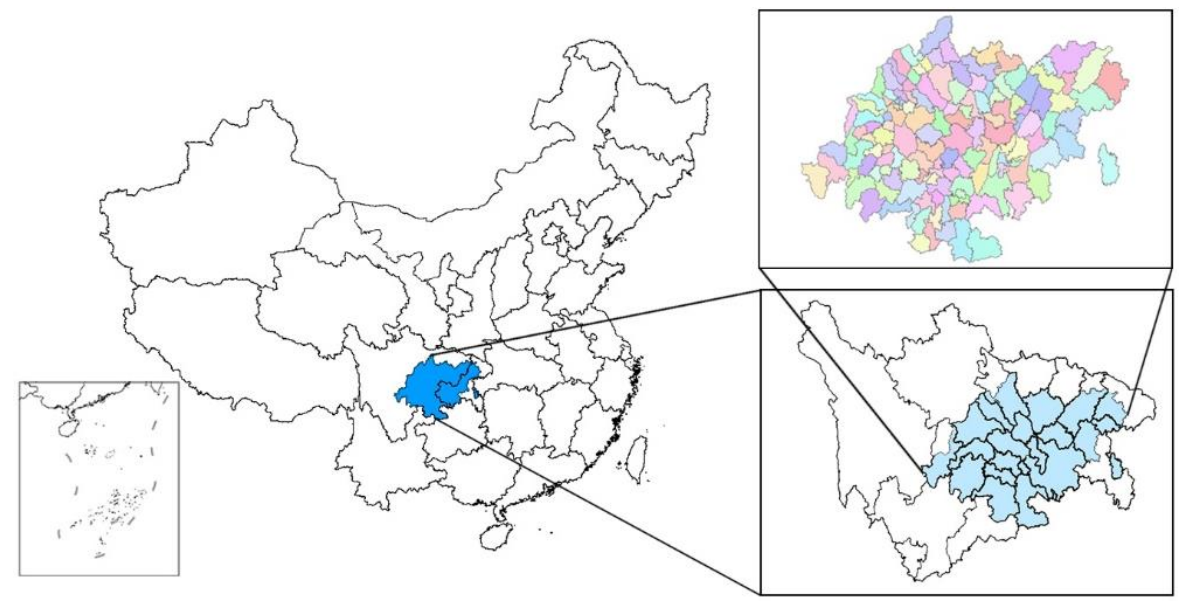

Fig.2 Geographical location of study area

\section{Index system}

The rapid development of Chengdu-Chongqing area has brought increasing pressure on the ecological environment. Economic growth is accompanied by a large amount of resource consumption and pollutant discharge. With the rapid development of urbanization, the urban ecological environment is gradually deteriorating. In order to measure the interaction between the level of urbanization and natural resources in Chengdu-Chongqing area, this study constructed a PSRU model. The PSR model is widely used in resources(H. Liu \& Men, 2018; Q. Wang et al., 2013), ecological carrying capacity(Wei, Guo, Wu, \& Ye, 2014), and ecological safety assessment (Fan \& Fang, 2020; Sun, Li, Gao, \& Xia, 2018) and so on. The model is constructed from three directions: human consumption patterns, institutional conditions, and strategies to promote sustainable development, making the model systematic and causal. Then establish an index system to evaluate the degree of urbanization, and record it as the U subsystem. The research on urbanization mostly starts from economy, population, society, ecological environment and public services, while the selection of ecological environment indicators mostly starts from natural conditions and environmental governance. Therefore, the PSRU model can simultaneously reflect the 
comprehensive utilization of natural resources and the level of urbanization in the Chengdu-Chongqing Economic Circle.(Cui, Fang, Liu, \& Liu, 2019; Fang et al., 2019; Verma \& Raghubanshi, 2018). The specific model is shown in Fig.3. The $\mathrm{P}$ subsystem reflects the burden of urban development on environmental resources. The S subsystem reflects the total amount of urban ecological resources. The

$170 \mathrm{R}$ subsystem reflects the measures taken by various regions in response to ecological deterioration. The

171 U subsystem is composed of population, economy, environment and space. Due to the large differences

172 in urban development in Chengdu-Chongqing area, the P subsystem adopts an index that can reflect the

173 density to eliminate the influence of area on the index. The S subsystem and R subsystem reflect the

174 overall level of the area, so use indicators that reflect the total amount. The selection of U subsystem

175 indicators considers these two types. See Table 1 for specific indicators.

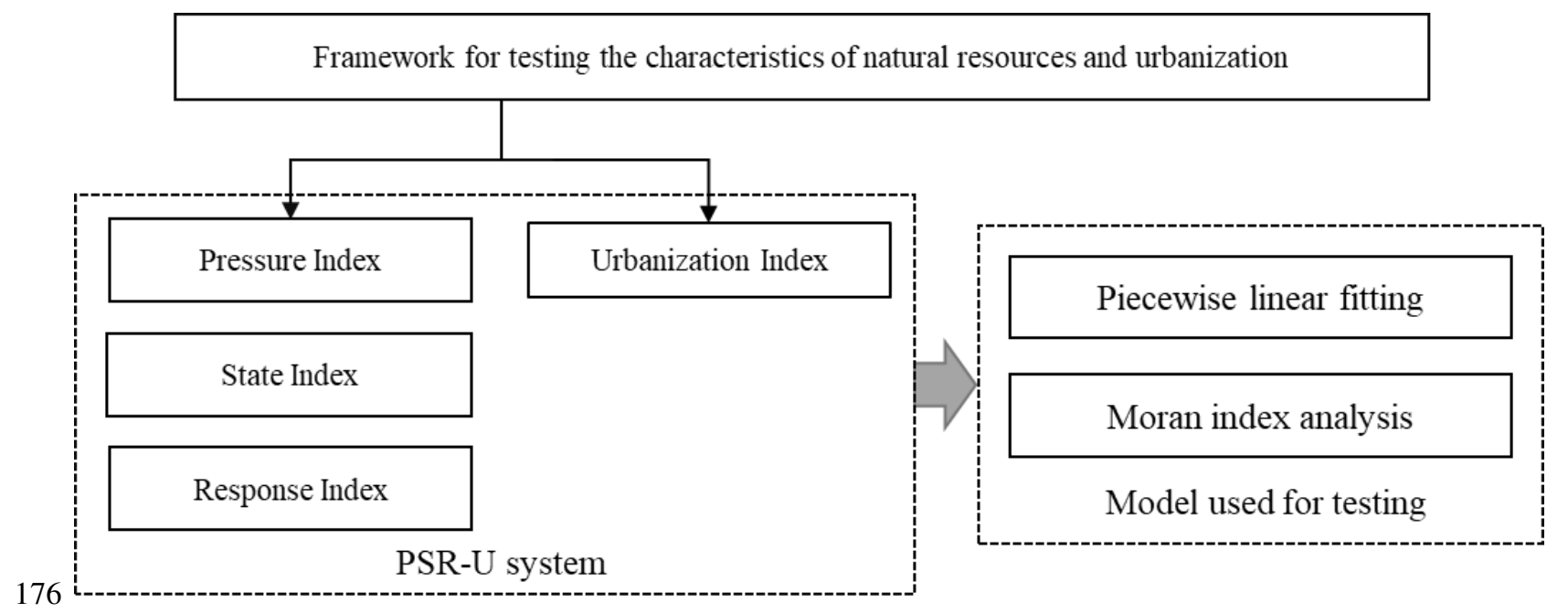

Fig.3 The relationship between the PSRU system

Table 1 PSRU system index system

\begin{tabular}{|c|c|c|c|c|}
\hline $\begin{array}{l}\text { Target } \\
\text { layer }\end{array}$ & Criteria layer & Indicator layer & Units & $\begin{array}{l}\text { Index } \\
\text { type }\end{array}$ \\
\hline \multirow[t]{11}{*}{ PSRU } & Pressure & Unit agricultural output value $\left(\mathrm{P}_{1}\right)$ & Ten thousand yuan of per sq. km & + \\
\hline & & Unit forestry output value $\left(\mathrm{P}_{2}\right)$ & Ten thousand yuan of per sq. km & + \\
\hline & & Per capita of water consumption $\left(\mathrm{P}_{3}\right)$ & $\mathrm{m} 3$ & + \\
\hline & & Energy consumption of per ten thousand industrial GDP $\left(\mathrm{P}_{4}\right)$ & $1 \mathrm{t}$ & + \\
\hline & State & Sown area of crops $\left(\mathrm{S}_{1}\right)$ & Hectares & + \\
\hline & & Total water resources $\left(\mathrm{S}_{2}\right)$ & $10^{8} \mathrm{~m}^{3}$ & + \\
\hline & & Forest area $\left(\mathrm{S}_{3}\right)$ & sq. km & + \\
\hline & & Comprehensive Air Quality Index $\left(\mathrm{S}_{4}\right)$ & & - \\
\hline & Response & Sewage treatment rate $\left(\mathrm{R}_{1}\right)$ & $\%$ & + \\
\hline & & Energy saving and environmental protection expenditure $\left(\mathrm{R}_{2}\right)$ & Ten thousand yuan & + \\
\hline & & Pollution prevention expenditure $\left(\mathrm{R}_{3}\right)$ & Ten thousand yuan & + \\
\hline
\end{tabular}




\begin{tabular}{|c|c|c|c|}
\hline & Decrease rate of fertilizer use $\left(\mathrm{R}_{4}\right)$ & $\%$ & + \\
\hline \multirow{4}{*}{ Urbanization } & GDP density $\left(\mathrm{U}_{1}\right)$ & Ten thousand yuan of per sq. $\mathrm{km}$ & + \\
\hline & The population density $\left(\mathrm{U}_{2}\right)$ & Person of per sq. km & + \\
\hline & Green coverage rate of built-up area $\left(\mathrm{U}_{3}\right)$ & $\%$ & + \\
\hline & Per capita public green area $\left(\mathrm{U}_{4}\right)$ & per capita of sq. m & + \\
\hline
\end{tabular}

180

\section{Quantify urban resource consumption and comprehensive development level}

182

\section{(1) Standardization}

The Chengdu-Chongqing Economic Circle includes 142 districts, and there are big differences in the level of urban development and the level of natural resource utilization.In order to compare regions with a large gap in development level, it is necessary to standardize the data first, and then quantify the consumption of ecological resources and the level of urban development. The standardized formula is as follows:

Positive index: $X_{\mathrm{ij}}^{\prime}=X_{i j}-\min \left(X_{j}\right) / \max \left(X_{j}\right)-$

$$
\min \left(X_{j}\right)
$$

$$
\text { Reverse index: } X_{\mathrm{ij}}^{\prime}=\max \left(X_{j}\right)-X_{i j} / \max \left(X_{j}\right)-\min \left(X_{j}\right)
$$

Where $X_{i j}^{\prime}$ is the standard value, $X_{i j}$ is the original value, $\max \left(X_{j}\right)$ is the maximum value of the $j$-th index of all samples, and $\min \left(X_{j}\right)$ is the minimum value of the $j$-th index of all samples.

(2) Entropy method

Entropy method is often used in the study of ecological and environmental problems (Fu, Zhuo, Song, Wang, \& Ren, 2020; He et al., 2021). Due to the characteristics of the entropy method, the weight of the subsystem can be determined by the degree of deviation of each index, which can better retain the characteristics of the data and reduce the loss of information. Therefore, this study chooses to use the entropy method to process the data in the PSRU system. Import the standardized data into the entropy formula, the calculation formula is as follows:

$$
\begin{gathered}
P_{\mathrm{ij}}=X_{\mathrm{ij}}^{\prime} / \sum_{i=1}^{n} X_{\mathrm{ij}}^{\prime} \\
e_{i}=-\frac{1}{\ln (n)} \sum_{j=1}^{m} P_{\mathrm{ij}} \ln P_{\mathrm{ij}} \\
W_{i}=\left(1-e_{i}\right) / \sum_{i=1}^{n}\left(1-e_{i}\right)
\end{gathered}
$$




$$
U_{j}=\sum_{j=1}^{m} X_{i j}^{\prime} W_{j}
$$

$X_{i j}^{\prime}$ represents the standardized value of the $i$-th index and the $j$-th area. $e_{i}$ and $W_{i}$ are the entropy and comprehensive weight corresponding to the index. $U_{j}$ represents the comprehensive development index of the area.

\section{Piecewise linear regression}

In order to show the relationship between the utilization of ecological resources and the development of urbanization, the PSR subsystem is the independent variable, and the $U$ subsystem is the dependent variable. Use Matlab to fit the scatter plot. The fitting method is to determine the straight line formed by the predicted value. At this time, there is the smallest absolute residual between the predicted value and the actual value. After testing, there is an obvious steering relationship between the PSR subsystem and the U subsystem, so piecewise linear regression is used for fitting(Toms \& Lesperance, 2003), and the fitting formula is summarized as follows:

$$
Y=\left\{\begin{array}{ccc}
\beta_{0}+\beta_{1} X_{i} & \text { for } & X_{i} \leq \alpha \\
\beta_{0}+\beta_{1} X_{i}+\beta_{2}\left(X_{i}-\alpha\right)+e_{i} & \text { for } & X_{i}>\alpha
\end{array}\right.
$$

$Y$ is the value of urbanization development level. $X_{\mathrm{i}}$ respectively refers to the corresponding value of the development level of the PSR subsystem. $e_{\mathrm{i}}$ is the error term, and $\alpha$ is the threshold.

\section{Spatial correlation analysis}

Spatial autocorrelation emphasizes spatial correlation. Spatial correlation includes positive correlation and negative correlation, both of which indicate significant correlation. The difference is that positive spatial correlation means the aggregation of spatial distribution positions, and negative spatial correlation means that spatial distribution positions are more discrete. Moran index can be used to analyze global correlation. After determining that the global correlation exists, in order to clarify the specific aggregation state, the local Moran index can be used. The global and local correlation Moran index formulas are as follows:

$$
I=\frac{\mathrm{n}}{\mathrm{S}_{0}} \times \frac{\sum_{i=1}^{n} \sum_{j=1}^{n} W_{i j}\left(Y_{i}-\bar{Y}\right)\left(Y_{j}-\bar{Y}\right)}{\sum_{i=1}^{n}\left(Y_{i}-\bar{Y}\right)^{2}}
$$

$$
I_{i}=\frac{Y_{i}-\bar{Y}}{S^{2}} \sum_{i=1, j \neq 1}^{n} W_{i j}\left(Y_{i}-\bar{Y}\right)
$$




$$
\bar{Y}=\frac{1}{n} \sum_{i=1}^{n} Y_{i}
$$

$I$ is the global Moran index, $I i$ is the local Moran index of the $i$-th area. $\mathrm{N}$ is the total number of spatial units. $Y_{i}$ and $Y_{j}$ represent the attribute values of unit $i$ and unit $j$, respectively. $W_{i j}$ is the spatial weight value.

\section{Mapping the spatial image of urbanization and ecological resources}

Chengdu-Chongqing regions have different resource conditions and different levels of urbanization. The quantified results of the PSRU system show different levels of comprehensive development in different regions. Therefore, the coefficients of P subsystem, S subsystem, R subsystem and U subsystem are respectively associated with the administrative boundary map of prefecture-level cities in the Chengdu-Chongqing urban agglomeration. Drawing the comprehensive coefficient map of each subsystem can directly reflect the development of the Chengdu-Chongqing economic circle.

\section{Results}

\section{Calculation of PSRU}

Formula (1) is used to calculate the entropy value of the PSRU system in the Chengdu-Chongqing area. The city abbreviations, raw data and PSRU system weights are shown in Table 2, Table 3 and Table 4, respectively. The comprehensive development level of Chengdu-Chongqing city is shown in Table 5. 


\begin{tabular}{lll}
\hline \multirow{3}{*}{ Response } & Comprehensive Air Quality Index $\left(\mathrm{S}_{4}\right)$ & 0.135 \\
& Sewage treatment rate $\left(\mathrm{R}_{1}\right)$ & 0.106 \\
& Energy saving and environmental protection expenditure $\left(\mathrm{R}_{2}\right)$ & 0.250 \\
& Pollution prevention expenditure $\left(\mathrm{R}_{3}\right)$ & 0.379 \\
\multirow{3}{*}{ Urbanization } & 0.265 \\
& Decrease rate of fertilizer use $\left(\mathrm{R}_{4}\right)$ & 0.298 \\
& GDP density $\left(\mathrm{U}_{1}\right)$ & 0.288 \\
& The population density $\left(\mathrm{U}_{2}\right)$ & 0.111 \\
& Green coverage rate of built-up area $\left(\mathrm{U}_{3}\right)$ & 0.304 \\
\hline
\end{tabular}

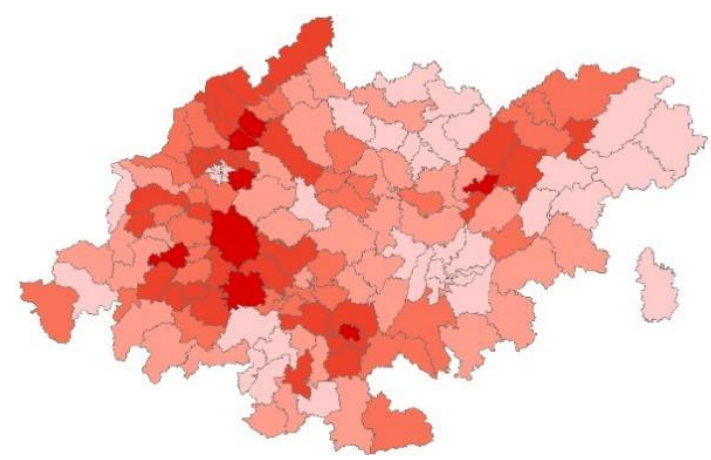

(a) Distribution of P subsystem

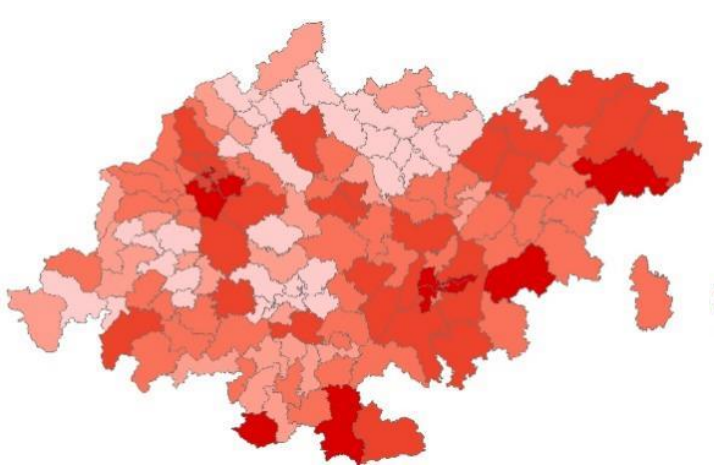

(c) Distribution of R subsystem

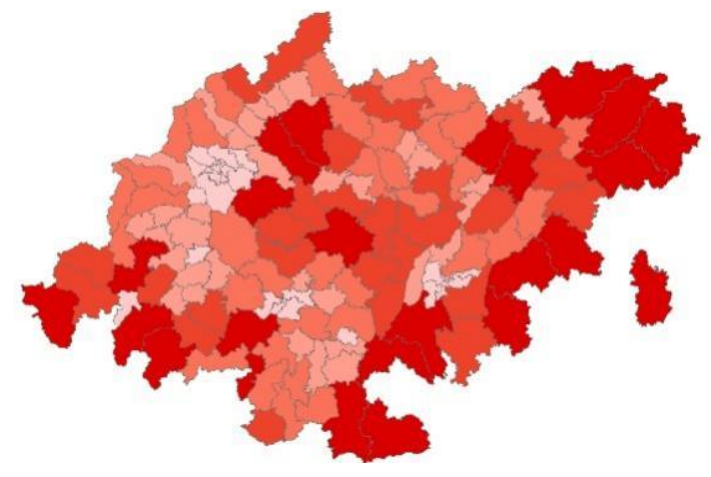

(b) Distribution of S subsystem

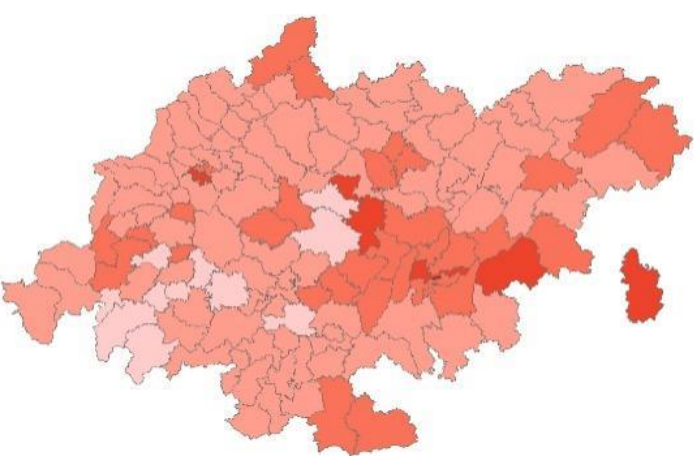

(d) Distribution of U subsystem

Fig. 4 Comprehensive development level of PSRU subsystem

The spatial distribution of the development status of the PSRU system is shown in Fig.4. There are obvious spatial differences between the subsystems. The comprehensive development level of the $\mathrm{P}$ subsystem is between 0.031 and 0.610 , and the overall resource consumption pressure of Chongqing is significantly lower than that of Sichuan. The lowest city is YZ, and the highest is RS. It can be seen from Table 4 that Chongqing's demand for land, forest, water and energy is mostly lower than that of Sichuan. to a relatively high resource utilization efficiency in Chongqing, or a more environmentally friendly 
industrial structure. For example, in $\mathrm{YZ}$, the resource pressure is the lowest and it is not engaged in agriculture and forestry production. In RS, where the pressure is the most, the intensity of agricultural and forestry production activities ranks in the forefront of the Chengdu-Chongqing urban agglomeration. In addition, water and industrial energy consumption in the region is in the middle.

The comprehensive level of the S subsystem is between 0.030 and 0.800 . On the whole, the level of natural resources in the southeast of the Chengdu-Chongqing Economic Circle is higher than that in the northwest. $\mathrm{XH}$ has the highest resource coefficient and $\mathrm{WH}$ has the lowest. The resource level of a city is closely related to the degree of urbanization and the region's own natural conditions. For example, $\mathrm{XH}$, which has the highest urbanization resource coefficient, is the city with the largest forest area in the Chengdu-Chongqing urban agglomeration, and the content of other natural resources also ranks in the forefront. In WH, where the state coefficient is the lowest, the level of urbanization is at the forefront of the Chengdu-Chongqing economic circle, and resources have been developed for a long time. Therefore, the content of various resources is relatively small, especially land resources and forest resources.

The coefficient range of the R subsystem is $0.058-0.666$, and the areas that attach importance to environmental protection are concentrated in the central and eastern regions of the Chengyu urban agglomeration. The highest is in SL, and the lowest is TC. The factors that have the greatest impact on investment in environmental governance are development-related policies formulated by local governments. Although most cities with high levels of urbanization pay attention to the implementation of environmental protection measures, some areas with slower development also attach importance to environmental protection. Therefore, there is no direct causal relationship between environmental protection investment and the level of urbanization, but there is an indirect relationship. For example, SL has a high level of urbanization. The city directly allocated a large amount of energy conservation and environmental protection funds and pollution prevention funds. However, in TC, the level of urbanization, environmental maintenance investment and pollution control levels are low.

The $\mathrm{U}$ subsystem is between $0.008-0.700$. The urbanization level of most cities is medium, and the cities with faster development are mainly concentrated in the center of Chengdu, YZ and the surrounding cities. The fastest growing city is YZ, and the lowest is AJ. Population concentration, preferential policies and good natural conditions can greatly promote the development of urbanization. For example, YZ has the highest GDP density and population density, and urban greening is also better. This is a characteristic of highly developed urbanization, and it also provides a good foundation for the sustainable development of urbanization. However, the development of $\mathrm{AJ}$ is slow, and the index coefficients such as population, economy and space are all at the end of Chengdu-Chongqing urban 

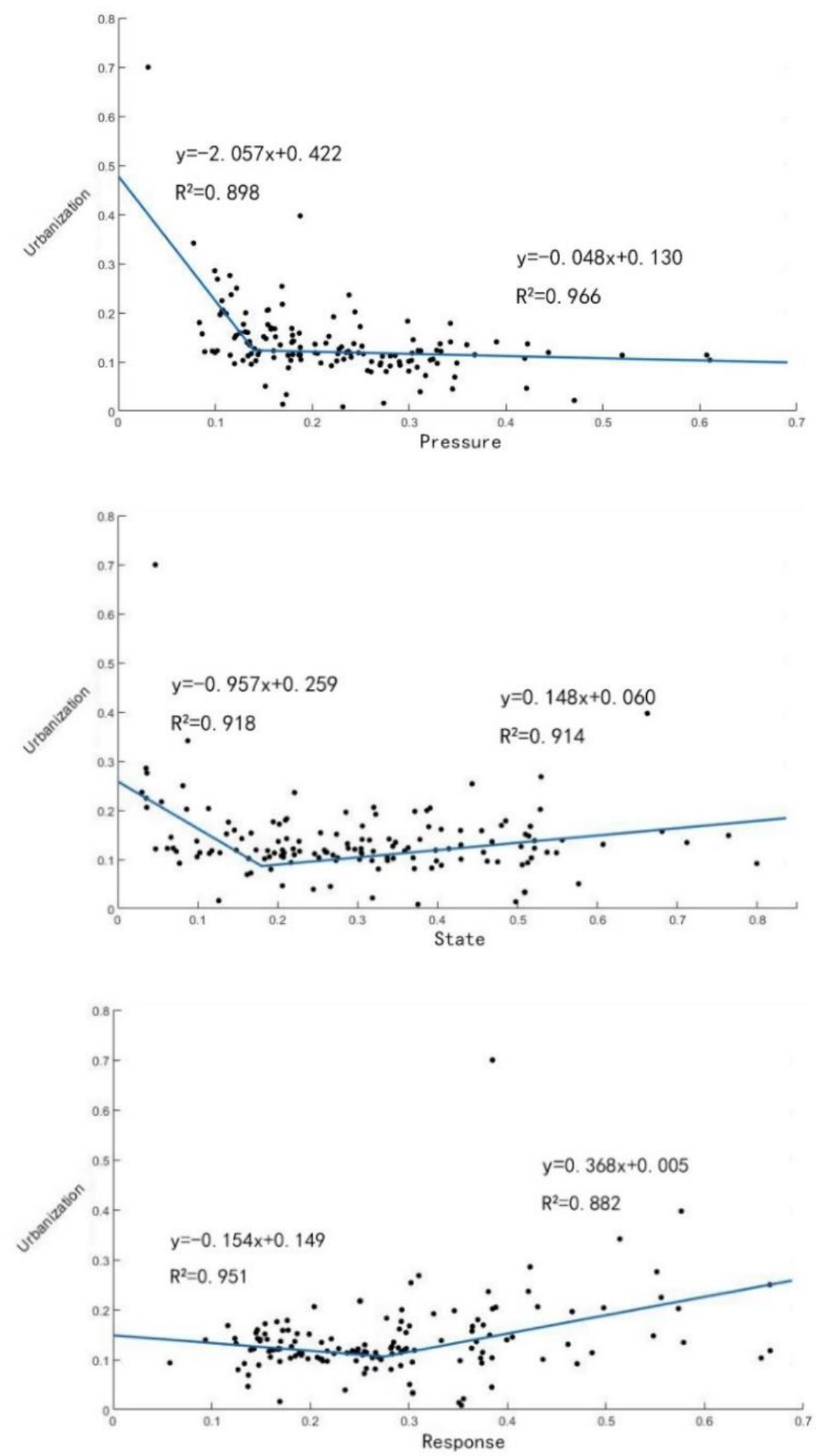
The response image of PSR to $U$ is shown in Fig. 5. The linear regression trend of PSRU system is: before reaching the threshold, the relationship between the U subsystem and the PSR subsystem is negatively correlated (abbreviated as N). After the threshold, there is a Low-level negative correlation (abbreviated as L) between $\mathrm{P}$ and $\mathrm{U}$, while the responses of $\mathrm{S}-\mathrm{U}$ and $\mathrm{R}-\mathrm{U}$ have become more obvious positive correlations (abbreviated as $\mathrm{P}$ ).

The response thresholds of PSR to $U$ are $0.145,0.180$ and 0.275 , respectively. The relationship between the P subsystem and U subsystem changes the fastest, followed by S subsystem and R subsystem. In addition, from the results of the piecewise regression, the slopes of the PSR subsystem before the threshold are $-2.057,-0.957$, and -0.154 , respectively. When the threshold is reached, the slopes become $-0.048,0.148$, and 0.368 , respectively. It can be concluded that before the mutation point, the P subsystem is the most sensitive to urbanization development, followed by the $\mathrm{S}$ subsystem, and the R subsystem is the least sensitive. After reaching the threshold, the sensitivity of the PSR system to the U subsystem gradually increases, and the most sensitive becomes the R subsystem.

In addition, the PSR system has 38, 34, and 75 cities before the threshold, and 104, 108, and 67 cities behind the threshold. Taking into account the meaning of the PSR system and the results of segmented regression, cities in different segments have different characteristics. The response relationship of the $\mathrm{P}$ subsystem to the $\mathrm{U}$ subsystem changes from $\mathrm{N}$ to $\mathrm{L}$. The number of cities before the threshold is $26.76 \%$. The pressure brought by the consumption of natural resources in this area will obviously affect the level of urbanization development. However, after reaching the threshold, the pressure on natural resources has not effectively transformed into a driving force for urbanization. The response relationship of the $\mathrm{S}$ subsystem to the $\mathrm{U}$ subsystem changes from $\mathrm{N}$ to $\mathrm{P}$. This means that before reaching the threshold, $23.94 \%$ of the cities have low total natural resources, but the resource content has a significant impact on the development of urbanization. After the threshold, there are more urban resources, which have a positive impact on urbanization, but the impact is relatively weak. On the one hand, it can be said that cities before the threshold can use natural resources more effectively. On the other hand, it also means that cities after the threshold still have great potential in the development of natural resources. The response of the $\mathrm{R}$ subsystem to the $\mathrm{U}$ subsystem first presents $\mathrm{N}$ and then becomes P. This means that the environmental protection measures in $52.82 \%$ of the regions are not in line with the level of urbanization before reaching the threshold. Urban environmental protection measures after the threshold are effective and can significantly promote urbanization. 
most of the cities with greater pressure on resource development are concentrated in areas with lower levels of urbanization. In the development process, ecological resources will inevitably be consumed. Therefore, in relatively underdeveloped areas, consuming resources is the most convenient way of development. The massive consumption of resources will bring more impetus to urban development. However, the regression relationship proves that the efficiency of resource development in these areas is low, and cities cannot develop rationally.

The state of natural resources reflects the amount of existing resources. Due to the slower development of resources in areas with low levels of urbanization, the amount of resource possession is higher than areas with high levels of urbanization. However, it can be seen from the S-U threshold image that the level of urbanization in the most resource-rich areas is moderate. This means that these cities are rich in natural resources and have huge development potential for the sustainable development of urbanization. In addition, natural resources in areas with high levels of urbanization are relatively scarce. The development of such urban resources is close to saturation, and more attention needs to be paid to the ecological environment.

The R coefficient reflects the city's investment in maintaining the ecosystem. Most areas with high levels of urbanization have higher environmental awareness than areas with relatively slow urbanization. At the same time, the cities most lacking in environmental protection measures are also cities with a medium level of urbanization. The reason for this phenomenon may be that cities with a medium urbanization level are more eager to achieve faster and better development, so they may ignore the implementation of environmental protection measures. However, it can be seen from the R-U threshold relationship that as the level of urbanization increases, the investment in environmental governance will eventually increase.

\subsection{Spatial correlation analysis}

\section{(1) Global autocorrelation}

The global Moran index of PSRU is shown in Table 6. Using the kernel function of GeoDa software to construct spatial weights, and 999 random tests are performed., and 999 random tests are performed. Univariate correlation reflects whether the subsystem itself is related, and bivariate correlation tests whether there is a correlation between the PSR subsystem and the U subsystem. The global Moran index test results show that the subsystems of PSRU are all $\mathrm{P}<0.01$ and the Moran index is positive, which means that each subsystem has a significant positive correlation, and the overall space has an 
366

agglomeration effect. The binary correlation test results show that both the $\mathrm{P}$ subsystem and the $\mathrm{S}$ subsystem have a significant negative correlation with the $\mathrm{U}$ subsystem $(\mathrm{P}<0.01, \mathrm{I}<0)$. The $\mathrm{R}$ subsystem and the $\mathrm{U}$ subsystem are significantly positively correlated $(\mathrm{P}<0.01, \mathrm{I}>0)$. After proving the significant existence of the global Moran index, the local Moran index can be used to test the clustering mode of urban agglomerations.

(2) Local autocorrelation

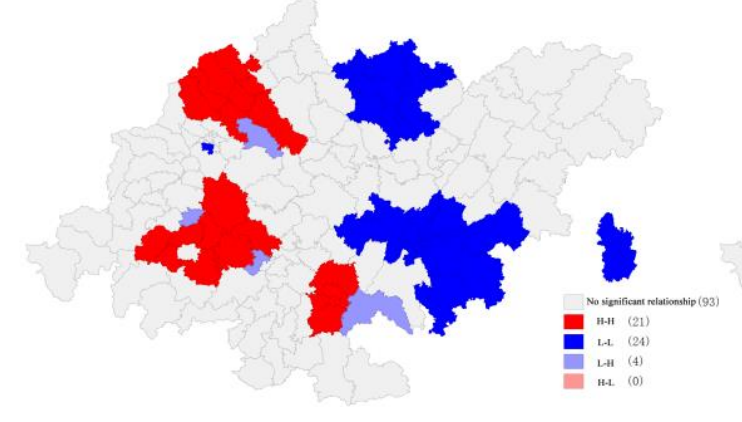

(a) Lisa diagram of P subsystem

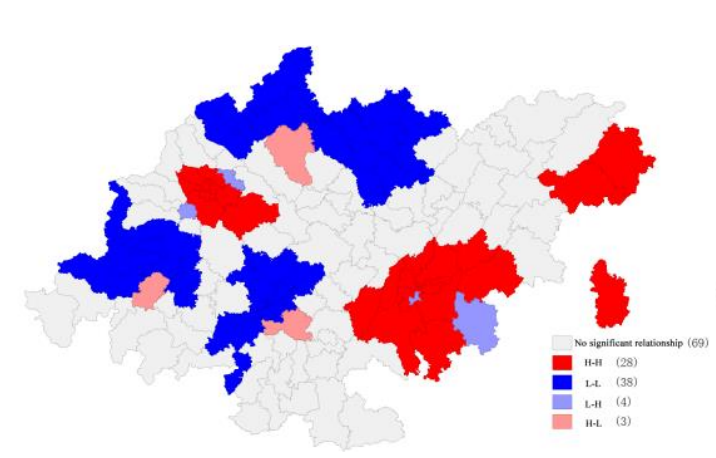

(c) Lisa diagram of R subsystem

Table 6 Moran Index Results

\begin{tabular}{lllllll}
\hline & \multicolumn{3}{l}{ Univariate correlation } & \multicolumn{4}{c}{ Bivariate correlation (to U) } \\
\cline { 2 - 7 } & Moran's I & $\mathrm{P}$ & $\mathrm{Z}$ & Moran's I & $\mathrm{P}$ & $\mathrm{Z}$ \\
\hline Pressure & 0.392 & 0.001 & 6.916 & -0.259 & 0.001 & -6.932 \\
State & 0.544 & 0.001 & 10.647 & -0.180 & 0.001 & -5.565 \\
Response & 0.526 & 0.001 & 10.159 & 0.359 & 0.001 & 10.407 \\
Urbanization & 0.456 & 0.001 & 9.5025 & $/$ & $/$ & $/$ \\
\hline
\end{tabular}

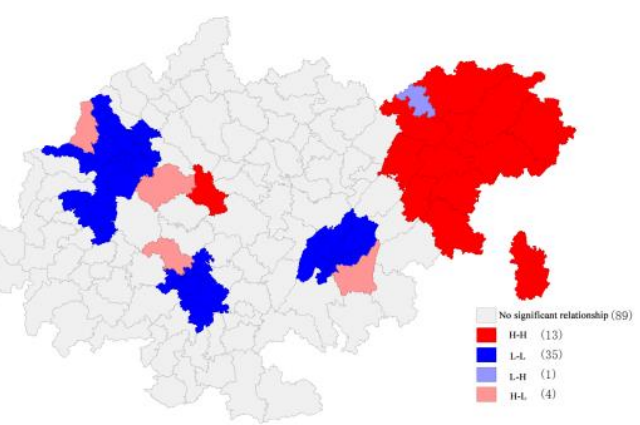

(b) Lisa diagram of S subsystem

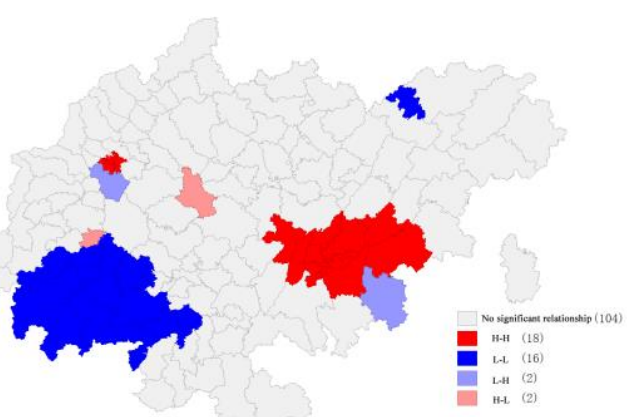

(d) Lisa diagram of U subsystem

Fig. 6 Lisa image of PSRU system

In order to clarify the agglomeration effect in Chengdu-Chongqing area, a local spatial correlation analysis was carried out. The Lisa diagram is shown in Fig.6. The colored cities are all cities with 


\section{Discussion} relationships.

significant correlation $(\mathrm{P}>0.05)$. According to the autocorrelation relationship, the Chengdu-Chongqing area can be divided into five categories: HH, LL, HL, LH and insignificant. They represent high-level agglomeration areas, low-level agglomeration areas, high-level cities but low-level areas surrounding them, low-level but high-level surrounding cities, and cities without significant agglomeration

Regardless of the regions with no significant relationship, the regions with significant correlation in the P subsystem can be divided into three types. HH type (21 cities) are mainly concentrated in Deyang, Leshan and Luzhou; LL type (24 cities) are mainly concentrated in Guangyuan and Yunnan area; LH type (4 cities) are distributed around HH area. It can be seen that cities with low-pressure clusters are in the majority. According to the aggregation effect of the S subsystem, there are four types. HH type (13 cities) are mainly distributed in northern Chongqing and Dazhou. Type LL (35 cities) are mainly distributed in the vicinity of Chengdu, Meishan, Zigong and Yuzhong District. Type LH (1 city) is located in Dazhou. Type LL (4 cities) exists in areas near LH. It can be found that in agglomerated areas, cities with fewer natural resources account for the majority. According to the agglomeration effect of the $\mathrm{R}$ subsystem, the regions with significant relationships can be divided into four categories. HH type (28 cities) are mainly distributed in Chengdu, Yuzhong, Yubei; LL type (38 cities) are mainly distributed in Deyang, Mianyang, Guangyuan, Ya'an, Meishan, Leshan, Neijiang, Zigong; LH and HL types are located respectively in Around $\mathrm{HH}$ and LL areas, and the two types of cities are less in number. It can be found that in areas where the correlation is significant, most cities lack effective environmental protection measures. According to the level of U subsystem, it can be divided into four categories. The HH type (18 cities) city has two gathering areas, one is located in the middle and lower part of Chongqing, such as $\mathrm{YZ}$, and the other is located in the center of Chengdu. LL type (16 cities) is concentrated in Leshan and Yibin. The number of HL and LH cities is still small. In areas with significant correlations, there are slightly more cities with high levels of urbanization than cities with slow urbanization. In short, the $\mathrm{HH}$ and LL cities in each subsystem are the most distributed features. The number of LH and HL is relatively small, and they are mainly distributed near HH and LL cities.

\section{Divide cities by threshold stage}




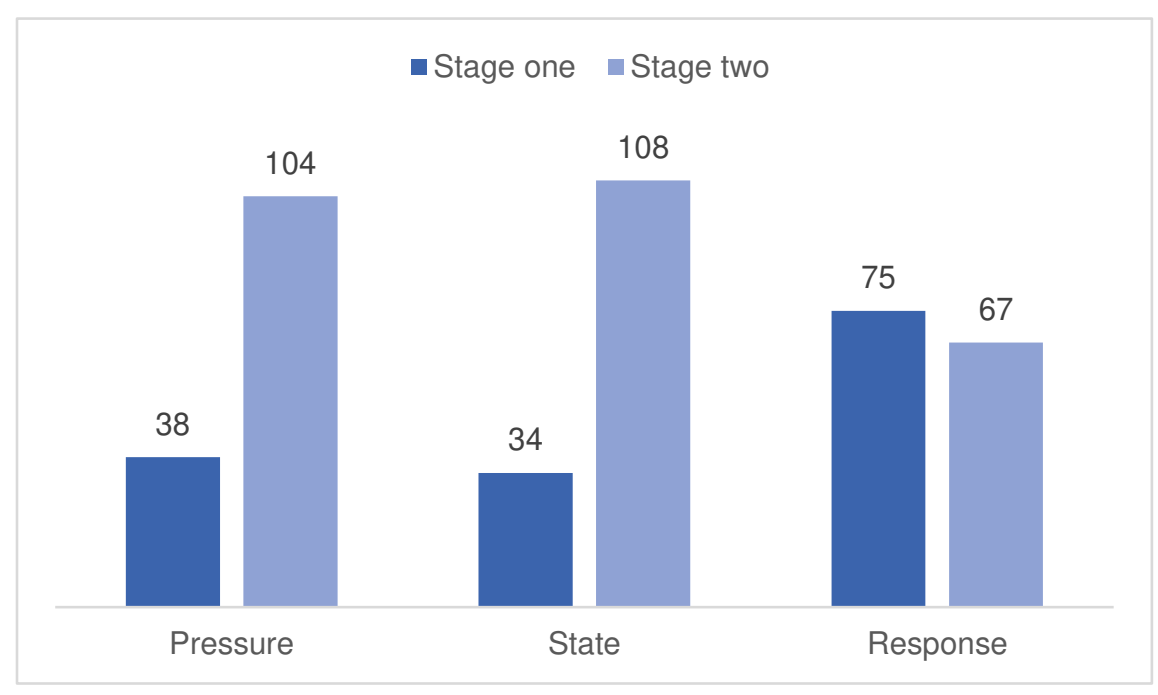

Fig. 7 Segment the response of the PSR system to the U system according to the threshold

The response of the PSR system to the U system is segmented according to the threshold, as shown in Fig.7, and it can be found that: (1) The cities in the first segment of the PSR system account for $26.76 \%$, $23.94 \%$, and $52.82 \%$ respectively. Judging from the response of the PS subsystem to the U subsystem, most cities are in the second stage. However, in the relationship of the response of the R subsystem to the $U$ subsystem, the number of cities in the two stages is roughly equal. This means that the main characteristics of natural resource utilization in the Chengdu-Chongqing Economic Circle are: The pressure of resource utilization is high, but it has not been effectively transformed into the driving force of urbanization. Rich in resources, but slow development of urbanization. Less than half of the cities have effective environmental maintenance measures, and most areas have less investment in environmental governance or poor results. (2)Analyze the number of cities in the two phases of the response of the U subsystem from the PS subsystem. The result shows that most cities in the ChengduChongqing area have a lot of resources, but they are unable to effectively transform the resources into development motives. However, this also shows that the Chengdu-Chongqing area still has great potential for resource development, and new technologies are needed to improve the efficiency of resource conversion power. The response of the $\mathrm{R}$ subsystem to the $\mathrm{U}$ subsystem indicates that there are slightly more cities in the first stage than in the second stage, which means that there are slightly more cities with ineffective environmental governance than effective cities. In general, the level of environmental maintenance is significantly higher than the level of natural resource utilization and resource development, which means that the environmental protection level of the Chengdu-Chongqing urban agglomeration is higher than the overall equilibrium state. 


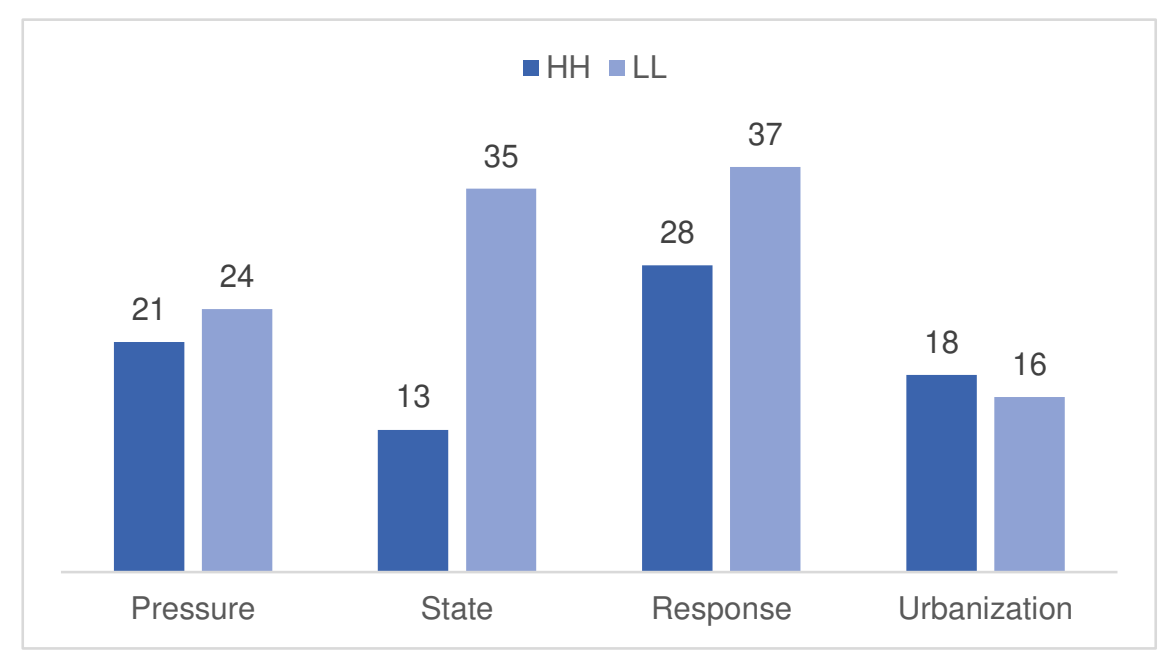

Fig. 8 Number of $\mathrm{HH}$ and LL cities in the PSR system

The HH and LL types of cities in the PSR system are shown in Fig. 8. In the PSRU system, the number of LL types in the PSR subsystem is greater than that of the HH type, and the proportions of LLtype cities are $53.33 \%, 72.92 \%$, and $56.92 \%$ respectively; In the U subsystem, the HH type is larger than the LL type, accounting for 52.94\%. In addition, the city types of the PU subsystem are relatively balanced, and the most unbalanced is the S subsystem.

It can be inferred that in areas with significant correlation, most cities are located in LL, LL, LL, and $\mathrm{HH}$ areas of the PSRU system. The following conclusions can be drawn:(1)Among the cities with greater relevance in the Chengdu-Chongqing region, the most common urban characteristics are less pressure on natural resources, insufficient resource levels, less investment in environmental protection, and higher levels of urbanization. (2)In areas with more prominent resource use characteristics, the most tense relationship is the level of natural resources, and areas lacking resources account for $72.92 \%$. It can be seen that with the development of urbanization, changes in resource content are more dramatic than changes in resource utilization pressure and protection measures.

\section{Combined analysis of segmented regression and aggregation effect}

Cities in the Chengdu-Chongqing area are classified according to the threshold: before the threshold is reached, the characteristic of PSR-U is N (the comprehensive development coefficient of the PSR subsystem before the threshold is in the range of 0.031-0.145, 0.030-0.180, and 0.058-0.275). After the 
446 threshold is reached, the characteristic of P-U is $\mathrm{L}(0.145-0.610)$, and the characteristic of SR-U is $\mathrm{P}$ $447(0.180-0.800,0.275-0.666)$. Matching the PSR system aggregation results with the threshold segment 448 type can define the characteristics of different types of cities. Since the local Moran index classification 449 results show that there are fewer cities in the LH and HL categories, only HH and LL cities are discussed 450 here. See Table 7 for specific classification. 
Table 7 Categorize cluster cities according to thresholds

\begin{tabular}{|c|c|c|c|c|c|c|c|c|}
\hline \multirow[t]{2}{*}{ Mean } & \multicolumn{2}{|l|}{ Pressure } & \multicolumn{2}{|l|}{ State } & \multicolumn{2}{|l|}{ Response } & \multicolumn{2}{|l|}{ Urbanization } \\
\hline & $\mathrm{HH}(21)$ & LL(24) & $\mathrm{HH}(13)$ & LL(35) & $\mathrm{HH}(28)$ & $\operatorname{LL}(38)$ & $\mathrm{HH}(18)$ & $\operatorname{LL}(16)$ \\
\hline $\mathrm{N}-\mathrm{N}-\mathrm{N}$ & & $\begin{array}{l}\text { SQ , GP } \\
(8.33 \%)\end{array}$ & & & & $\begin{array}{l}\text { SQ, GP } \\
(5.26 \%)\end{array}$ & & \\
\hline N-N-P & & $\begin{array}{l}\text { WH , SPB , JLP } \\
\text { JB , YZ, NA } \\
(25 \%)\end{array}$ & & $\begin{array}{l}\text { JN, QY, CH, JJ, WH, SPB, } \\
\text { JB, YZ, NA, JLP } \\
(28.57 \%)\end{array}$ & $\begin{array}{l}\text { SPB, JB, YZ, NA, JLP, } \\
\text { JN , CH, QY, WH, JJ } \\
(35.71 \%)\end{array}$ & & $\begin{array}{l}\mathrm{CH}, \mathrm{YZ,JB}, \mathrm{SPB}, J L P \\
\text {,NA,JJ,QY,JN,WH } \\
(55.56 \%)\end{array}$ & \\
\hline N-P-N & & $\begin{array}{l}\mathrm{LZ}, \mathrm{XC}, \mathrm{YL}, \mathrm{PA} \\
(16.67 \%)\end{array}$ & $\begin{array}{l}\mathrm{LZ} \\
(7.69 \%)\end{array}$ & & & $\begin{array}{l}\mathrm{LZ}, \mathrm{YT}, \mathrm{XC}, \mathrm{PA}, \mathrm{LS}, \\
\mathrm{YB}, \mathrm{YL} \\
(18.42 \%)\end{array}$ & & $\begin{array}{l}\mathrm{CP}, \mathrm{YB} \\
(12.5 \%)\end{array}$ \\
\hline N-P-P & & $\begin{array}{l}\mathrm{TL}, \mathrm{BS}, \mathrm{BB}, \\
\mathrm{YB}, \mathrm{BN}, \mathrm{QJ} \\
(25 \%)\end{array}$ & $\begin{array}{l}\text { KX , YY, WZ, LP, } \\
\text { DJ , ZX, QJ } \\
(53.85 \%)\end{array}$ & $\begin{array}{l}\mathrm{BB}, \mathrm{YB}, \mathrm{BS} \\
(8.57 \%)\end{array}$ & $\begin{array}{l}\text { YY, WZ, QJ , YB, } \\
\text { BB , BS , BN , JY } \\
(28.57 \%)\end{array}$ & $\begin{array}{l}\text { YL } \\
(2.63 \%)\end{array}$ & $\begin{array}{l}\mathrm{BB}, \mathrm{BN}, \mathrm{YB}, \mathrm{BS}, \mathrm{TL} \\
(27.78 \%)\end{array}$ & \\
\hline L-N-N & $\begin{array}{l}\text { QBJ, SW, LMT } \\
(14.29 \%)\end{array}$ & $\begin{array}{l}\text { DDK } \\
(4.17 \%)\end{array}$ & & $\begin{array}{l}\text { QBJ, XJ, PJ, QS , NJSZ, } \\
\text { DA, GJ , ZLJ, YT , DDK } \\
(28.57 \%)\end{array}$ & & $\begin{array}{l}\text { FC , DL , PJ , QS , WTQ , } \\
\text { NJSZ, DA, GJ , ZLJ , YT } \\
(26.32 \%)\end{array}$ & $\begin{array}{l}\text { DDK } \\
(5.56 \%)\end{array}$ & $\begin{array}{l}\text { JKH,SW,WTQ } \\
(18.75 \%)\end{array}$ \\
\hline L-N-P & & & & $\begin{array}{l}\text { XD , PD , WJ , SL , LQY } \\
(14.29 \%)\end{array}$ & $\begin{array}{l}\mathrm{PD}, \mathrm{XD}, \mathrm{WJ}, \mathrm{LQY}, \\
\mathrm{SL}(17.86 \%)\end{array}$ & & & \\
\hline L-P-N & $\begin{array}{l}\mathrm{AX}, \mathrm{MZ}, \mathrm{SF}, \mathrm{LJ}, \\
\mathrm{CN}, \mathrm{GH}, \mathrm{ZJ}, \mathrm{JY}, \\
\text { LSSZ, QW, WY, } \\
\text { JY, NX } \\
(61.90 \%)\end{array}$ & $\begin{array}{l}\mathrm{NB} \\
(4.17 \%)\end{array}$ & $\begin{array}{l}\mathrm{KJ} \\
(7.69 \%)\end{array}$ & $\begin{array}{l}\text { GH , CZ, DP, NX } \\
(11.43 \%)\end{array}$ & & $\begin{array}{l}\text { JY, AX, MZ, ZT, YX, } \\
\text { LJ , JY, NB , JL, YJ , } \\
\text { YC , MS , HY, DP , JJ(3), } \\
\text { LS , LSSZ, ZZ, DX, WY } \\
(52.63 \%)\end{array}$ & & $\begin{array}{l}\text { JY,LSSZ,QW } \\
\text {,MC,PS,NX,TC } \\
(43.75 \%)\end{array}$ \\
\hline L-P-P & $\begin{array}{l}\text { ST, RS , EMS , RX, } \\
\text { LX } \\
(23.81 \%)\end{array}$ & $\begin{array}{l}\mathrm{DZ}, \mathrm{FL}, \mathrm{NC}, \mathrm{QJ} \\
(16.67 \%)\end{array}$ & $\begin{array}{l}\mathrm{XH}, \mathrm{DZ}(1) \\
\mathrm{DZ}(2), \mathrm{FD} \\
(30.77 \%)\end{array}$ & $\begin{array}{l}\mathrm{PS}, \mathrm{PZ}, \mathrm{FS} \\
(8.57 \%)\end{array}$ & $\begin{array}{l}\mathrm{FL}, \mathrm{YC}, \mathrm{JJ}(2), \mathrm{ZJ}, \mathrm{CS} \\
(17.86 \%)\end{array}$ & & $\begin{array}{l}\text { CS,FL } \\
(11.11 \%)\end{array}$ & $\begin{array}{l}\text { RX,MBYZ, } \\
\text { EMS,EBYZ } \\
(25 \%)\end{array}$ \\
\hline
\end{tabular}


From the perspective of the overall development characteristics of the Chengdu-Chongqing area, the main characteristics of the PSRU system in HH and LL cities are different. The main feature of the HH type area in the P subsystem is L-P-N, which accounts for $61.90 \%$ of the total number of HH types. The main feature of the LL type area is N-N-P and N-P-P, both accounting for $25 \%$. The main characteristic of the HH type area of the S subsystem is N-P-P, accounting for $53.85 \%$, and the main characteristic of the LL type area is N-N-P and L-N-N, both accounting for $28.57 \%$. The main characteristics of the $\mathrm{HH}$ type region in the R subsystem are N-N-P and N-P-P, accounting for $35.71 \%$ and $28.57 \%$, respectively, and the main characteristic of the LL type is L-P-N, accounting for $52.63 \%$. The main feature of the HH type area of the U subsystem is N-N-P, which accounts for $55.56 \%$, and the main feature of the LL type is L-P-N and L-P-P, which account for $43.75 \%$ and $25 \%$, respectively. The conclusions that can be drawn are: (1) The PSU subsystem is relatively concentrated in the HH type area, and the R subsystem is more concentrated in the LL type area, and the number of cities of the same type exceeds $50 \%$. (2) Although the main characteristics of the spatial aggregation of the PSRU system are different, it can be found that there is an obvious connection between the $\mathrm{P}$ subsystem and the $\mathrm{S}$ subsystem: the main relationship between natural resource pressure and environmental maintenance is N-P and L-N. Areas with high utilization efficiency of natural resources often have active and effective environmental protection measures, while areas with low utilization efficiency are more likely to neglect environmental governance and maintenance.

Specifically, in areas with significant concentration of pressure, most of the resource utilization characteristics of HH cities are L-P-N. This shows that in areas where high pressure is concentrated, the utilization efficiency of ecological resources is generally low and resources are relatively abundant, but environmental protection investment is still insufficient. Among the LL cities, most of the urban PSR response characteristics to $U$ are negative correlation, negative correlation, positive correlation or negative correlation, positive correlation, and positive correlation. The number of cities in the two is roughly the same. This shows that in areas where low pressure is concentrated, most cities' consumption of natural resources can effectively promote the development of urbanization, and they attach great importance to the effective implementation of environmental protection measures. The difference between the second category and the former is that the latter has more resources, and the higher the level of resources, the better the development of urbanization in areas.

In areas with high concentration of resources, the overall characteristic of most cities belonging to the HH type is that the PSR system has an N-P-P relationship with the U subsystem, followed by an L- 
protection of the ecological environment, and can effectively promote urbanization by consuming natural resources. In LL-type cities, the relationship between PSR systems and U-subsystems has two main characteristics: N-N-P and L-N-N. The former has low level of natural resources, high efficiency of utilization and environmental protection. The latter has low level of resources, low utilization efficiency, and neglects the implementation of environmental governance measures. In addition, comparing the two types of cities, we can find that the former level of urbanization is significantly higher than the latter.

In areas where the spatial coefficients of the $\mathrm{R}$ subsystem are relatively concentrated, the main characteristic of HH-type cities is N-N-P, followed by N-P-P. In the former category of cities, consuming natural resources can effectively promote the development of urbanization. Despite the shortage of resources, effective environmental protection measures have been taken. The latter not only can efficiently use resources and protect the environment, but also has abundant ecological resources. The characteristics of resource use in LL cities are mainly L-P-N, followed by L-N-N. It can be seen that in most areas with insufficient environmental protection, resources cannot be effectively transformed into a driving force for urbanization. In addition, most of the cities where the R subsystem has a significant relationship are rich in resources. From the perspective of urbanization, the main characteristic of $\mathrm{H}-\mathrm{H}$ type areas is N-N-P, which means that areas with rapid urbanization development and significant concentration have high resource conversion efficiency. Although the resource content is small, environmental protection is emphasized. The characteristics of the LL-type are mainly L-P-N, followed by L-P-P. Both types of cities cannot effectively use natural resources, but generally have abundant natural resources. The difference between the two is that in areas with slow urbanization, most cities do not pay attention to environmental protection.

Based on the above content, in view of the characteristics of the resource usage in the four directions of the PSRU system, the following suggestions can be made:

(1) From the perspective of the relationship between resource development and urbanization, areas with high pressure on natural resource development tend to have lower utilization efficiency. Government departments should learn from the effective policies and measures implemented by lowpressure clusters, and improve the distribution relationship between renewable energy and nonrenewable energy development according to their own regional characteristics, so as to achieve sustainable economic, social and environmental development. Pay attention to the development of science and technology, increase investment in new technology research, encourage the use of environmentally friendly energy, promote the popularization of supporting facilities in high-pressure areas, and accelerate industrial transformation. At the same time, it is necessary to increase investment 
in environmental protection, improve the efficiency of effective resource management, strengthen supervision of high-polluting industries, and ensure that the development of various resources and the discharge of pollutants meet the standards.

(2) Starting from the impact of resource levels on the development of urbanization, most areas with high coefficients attach great importance to environmental protection, but some cities have poor resource utilization efficiency. Government departments can appropriately encourage resource development in these areas and develop local superior resources. For example, constructing water conservancy and hydropower projects in areas rich in water resources, and strengthening the development of coal, natural gas and other resources in areas rich in mineral resources to promote the further development of urbanization. In areas with low resource levels, government departments must first change the direction of urban development, such as developing tourist cities, attracting tourists with unique cultural traditions and natural landscapes, and promoting the tertiary industry to drive urban development. Increase investment in renewable energy development and increase the proportion of renewable energy in urban energy utilization. Promoting the promotion and use of clean energy can alleviate the pressure on the environment caused by urban development.

(3) From the perspective of environmental protection, the focus should be placed on areas with low coefficients of concentration. The urbanization process in these areas is slow, and no more funds are invested in environmental protection. Therefore, the government needs to formulate relevant measures to ensure that environmental maintenance and urban development are carried out simultaneously. For cities with superior basic conditions, rationally plan urban space and transportation to create favorable conditions for resource development and economic development. In addition, we must attach importance to human capital education and raise awareness of environmental protection. In regions without a rich natural resource base, it is difficult to obtain development momentum from the environment. On the one hand, it can tap its own regional characteristics, develop traditional culture according to local conditions and build a tourist city. On the other hand, development projects in these areas also need policy support to attract talent inflow and drive urban development.

\section{Conclusions}

This paper starts with the interaction between natural resources and urbanization, and builds a comprehensive system that reflects resource consumption and urbanization development. First, use the entropy method for data processing. Subsequently, the piecewise linear regression method was used to 
reflect the response characteristics of the PSR system to urbanization. The Moran index is used to reflect the spatial agglomeration effect of the Chengdu-Chongqing urban agglomeration. Finally, the results of the piecewise regression are combined with the local spatial agglomeration effect to analyze. The specific conclusions of the study are as follows:

(1) There is a threshold between stress, state, and response to urbanization. According to the regression relationship of the PSR system to the U subsystem, it can be found that the main characteristics of the comprehensive utilization of natural resources in Chengdu-Chongqing area are: high pressure on resource utilization, rich resource content, and poor environmental governance. Most cities cannot effectively use resources and turn them into a driving force for urbanization. This also represents the huge potential for resource development in Chengdu-Chongqing area, and it is necessary to improve the efficiency of transforming resources into driving forces for urban development. In addition, most areas have less investment in environmental governance, or poor results. However, from the perspective of the matching phase of the use characteristics during the development of urban agglomerations, the comprehensive development level of environmental protection in Chengdu-Chongqing area is significantly higher than the utilization efficiency and development level of natural resources.

(2) Each subsystem of the PSRU system has different aggregation characteristics in space. In areas with obvious agglomeration effects, the most common features are: less pressure on natural resources, obviously insufficient resource levels, less investment in environmental protection, and higher levels of urbanization. Among them, the most important feature is the content of natural resources. Because with the development of urbanization in Chengdu-Chongqing area, changes in resource levels are more drastic than changes in resource utilization pressures and protection measures.

(3) Combining the segmented regression of the PSR system to the U subsystem and the local spatial aggregation effect of the PSRU system, the following conclusions can be drawn. In cities that meet HH and LL types, the stage where the pressure has less impact on urbanization is matched with inefficient environmental protection measures. The stage where pressure and urbanization are significantly negatively correlated with efficient and active environmental protection measures. This shows that in areas where the agglomeration effect is significant, the relationship between the pressure on the use of natural resources and environmental protection measures is matched with each other. However, regardless of the correspondence between the PR subsystems, the S subsystems may be at different stages.

(4) For areas where the comprehensive utilization of resources and the stage of urban development are not balanced, the following measures can be taken: First, in terms of energy development and utilization, improve the distribution relationship between renewable and non-renewable energy, and 
579 encourage the use of environmentally friendly energy. The second is to increase capital investment to promote the research and promotion of new technologies for the efficient use of energy. Reduce the impact of resource utilization on urban development and cultivate diversified urban development momentum. In addition, reasonable planning of urban space and transportation to avoid ineffective and repeated use of resources. Finally, pay attention to manpower education, increase investment in environmental protection, and improve the efficiency of effective resource management. 


\section{References}

Ahmed, Z., Asghar, M. M., Malik, M. N., \& Nawaz, K. (2020). Moving towards a sustainable environment: The dynamic linkage between natural resources, human capital, urbanization, economic growth, and ecological footprint in China. Resources Policy, 67. doi:10.1016/j.resourpol.2020.101677

Cui, X., Fang, C., Liu, H., \& Liu, X. (2019). Assessing sustainability of urbanization by a coordinated development index for an Urbanization-Resources-Environment complex system: A case study of Jing-Jin-Ji region, China. Ecological Indicators, 96, 383-391. doi:10.1016/j.ecolind.2018.09.009

Ding, Y., \& Peng, J. (2018). Impacts of Urbanization of Mountainous Areas on Resources and Environment: Based on Ecological Footprint Model. Sustainability, 10(3). doi:10.3390/su10030765

Fan, Y., \& Fang, C. (2020). Evolution process and obstacle factors of ecological security in western China, a case study of Qinghai province. Ecological Indicators, 117. doi:10.1016/j.ecolind.2020.106659

Fang, C., Cui, X., Li, G., Bao, C., Wang, Z., Ma, H., . . Ren, Y. (2019). Modeling regional sustainable development scenarios using the Urbanization and Eco-environment Coupler: Case study of Beijing-Tianjin-Hebei urban agglomeration, China. Sci Total Environ, 689, 820-830. doi:10.1016/j.scitotenv.2019.06.430

Francesco Ficetola, G., \& Deno Ã«l, M. (2009). Ecological thresholds: an assessment of methods to identify abrupt changes in speciesâ $\square \square$ habitat relationships. Ecography, 32(6), 1075-1084. doi:10.1111/j.1600-0587.2009.05571.x

Fu, S., Zhuo, H., Song, H., Wang, J., \& Ren, L. (2020). Examination of a coupling coordination relationship between urbanization and the eco-environment: a case study in Qingdao, China. Environ Sci Pollut Res Int, 27(19), 23981-23993. doi:10.1007/s11356-020-08683-7

Garabedian, J. E., Moorman, C. E., Nils Peterson, M., \& Kilgo, J. C. (2017). Use of LiDAR to define habitat thresholds for forest bird conservation. Forest Ecology and Management, 399, 24-36. doi:10.1016/j.foreco.2017.05.024

Haase, D., Frantzeskaki, N., \& Elmqvist, T. (2014). Ecosystem services in urban landscapes: practical applications and governance implications. Ambio, 43(4), 407-412. doi:10.1007/s13280-014- 
He, G., Bao, K., Wang, W., Zhu, Y., Li, S., \& Jin, L. (2021). Assessment of ecological vulnerability of resource-based cities based on entropy-set pair analysis. Environ Technol, 42(12), 1874-1884. doi:10.1080/09593330.2019.1683611

IEA. (2008). World energy outlook 2008. IEA, Paris.

Li, C., Li, J., \& Wu, J. (2013). Quantifying the speed, growth modes, and landscape pattern changes of

Li, J., Li, C., Zhu, F., Song, C., \& Wu, J. (2013). Spatiotemporal pattern of urbanization in Shanghai, China between 1989 and 2005. Landscape Ecology, 28(8), 1545-1565. doi:10.1007/s10980013-9901-1

Li, K., Jin, X., Ma, D., \& Jiang, P. (2019). Evaluation of Resource and Environmental Carrying Capacity of China's Rapid-Urbanization Areas_-A Case Study of Xinbei District, Changzhou. Land, 8(4). doi:10.3390/land8040069

Li, Y., Cao, Z., Long, H., Liu, Y., \& Li, W. (2017). Dynamic analysis of ecological environment combined with land cover and NDVI changes and implications for sustainable urban-rural development: The case of Mu Us Sandy Land, China. Journal of Cleaner Production, 142, 697-715. doi:10.1016/j.jclepro.2016.09.011

Liu, H., \& Men, B. (2018). Water resource system vulnerability assessment of the Heihe River Basin based on pressure-state-response (PSR) model under the changing environment. Water Supply, 18(6), 1956-1967. doi:10.2166/ws.2018.017

Liu, W., Holst, J., \& Yu, Z. (2014). Thresholds of landscape change: a new tool to manage green infrastructure and social-economic development. Landscape Ecology, 29(4), 729-743. doi:10.1007/s10980-014-0007-1

Liu, Y. (2014). Is the natural resource production a blessing or curse for China's urbanization? Evidence from a space-time panel data model. Economic Modelling, 38, 404-416. doi:10.1016/j.econmod.2014.01.023

Liu, Y. (2018). Introduction to land use and rural sustainability in China. Land Use Policy, 74, 1-4. doi:10.1016/j.landusepol.2018.01.032

Madlener, R., \& Sunak, Y. (2011). Impacts of urbanization on urban structures and energy demand: What can we learn for urban energy planning and urbanization management? Sustainable Cities and Society, 1(1), 45-53. doi:10.1016/j.scs.2010.08.006 
McDonald, R. I., Green, P., Balk, D., Fekete, B. M., Revenga, C., Todd, M., \& Montgomery, M. (2011). Urban growth, climate change, and freshwater availability. Proc Natl Acad Sci US A, 108(15), 6312-6317. doi:10.1073/pnas.1011615108

McDonald, R. I., Weber, K., Padowski, J., Flörke, M., Schneider, C., Green, P. A., . . Montgomery, M. (2014). Water on an urban planet: Urbanization and the reach of urban water infrastructure. Global Environmental Change, 27, 96-105. doi:10.1016/j.gloenvcha.2014.04.022

Nathaniel, S. P., Nwulu, N., \& Bekun, F. (2021). Natural resource, globalization, urbanization, human capital, and environmental degradation in Latin American and Caribbean countries. Environ Sci Pollut Res Int, 28(5), 6207-6221. doi:10.1007/s11356-020-10850-9

Peng, J., Shen, H., Wu, W., Liu, Y., \& Wang, Y. (2015). Net primary productivity (NPP) dynamics and associated urbanization driving forces in metropolitan areas: a case study in Beijing City, China. Landscape Ecology, 31(5), 1077-1092. doi:10.1007/s10980-015-0319-9

Peng, J., Tian, L., Liu, Y., Zhao, M., Hu, Y., \& Wu, J. (2017). Ecosystem services response to urbanization in metropolitan areas: Thresholds identification. Sci Total Environ, 607-608, 706-714. doi:10.1016/j.scitotenv.2017.06.218

Peng, T., \& Deng, H. (2021). Evaluating urban resource and environment carrying capacity by using an innovative indicator system based on eco-civilization-a case study of Guiyang. Environ Sci Pollut Res Int, 28(6), 6941-6955. doi:10.1007/s11356-020-11020-7

Ramachandra, T. V., Bharath, A. H., \& Sowmyashree, M. V. (2015). Monitoring urbanization and its implications in a mega city from space: spatiotemporal patterns and its indicators. $J$ Environ Manage, 148, 67-81. doi:10.1016/j.jenvman.2014.02.015

Shahbaz, M., Loganathan, N., Muzaffar, A. T., Ahmed, K., \& Ali Jabran, M. (2016). How urbanization affects CO 2 emissions in Malaysia? The application of STIRPAT model. Renewable and Sustainable Energy Reviews, 57, 83-93. doi:10.1016/j.rser.2015.12.096

Sun, J., Li, Y. P., Gao, P. P., \& Xia, B. C. (2018). A Mamdani fuzzy inference approach for assessing ecological security in the Pearl River Delta urban agglomeration, China. Ecological Indicators, 94, 386-396. doi:10.1016/j.ecolind.2018.07.011

Toms, J. D., \& Lesperance, M. L. (2003). Piecewise regression: a tool for identifying ecological thresholds. Ecology, 84, 2034-2041.

Topcu, E., Altinoz, B., \& Aslan, A. (2020). Global evidence from the link between economic growth, natural resources, energy consumption, and gross capital formation. Resources Policy, 66. doi:10.1016/j.resourpol.2020.101622 
680

681

682

683

684

685

686

687

688

689

690

691

692

UN. (2012). World Urbanization Prospects: the 2011 revision.

Verma, P., \& Raghubanshi, A. S. (2018). Urban sustainability indicators: Challenges and opportunities. Ecological Indicators, 93, 282-291. doi:10.1016/j.ecolind.2018.05.007

Wang, K., Wu, M., Sun, Y., Shi, X., Sun, A., \& Zhang, P. (2019). Resource abundance, industrial structure, and regional carbon emissions efficiency in China. Resources Policy, 60, 203-214. doi:10.1016/j.resourpol.2019.01.001

Wang, Q., Yuan, X., Zhang, J., Mu, R., Yang, H., \& Ma, C. (2013). Key evaluation framework for the impacts of urbanization on air environment - A case study. Ecological Indicators, 24, 266-272. doi:10.1016/j.ecolind.2012.07.004

Wei, C., Guo, Z., Wu, J., \& Ye, S. (2014). Constructing an assessment indices system to analyze integrated regional carrying capacity in the coastal zones - A case in Nantong. Ocean \& Coastal Management, 93, 51-59. doi:10.1016/j.ocecoaman.2014.02.009 


\section{Appendix}

694

Table 2 Abbreviation of Chengyu Urban Agglomeration

\begin{tabular}{|c|c|c|c|c|c|c|c|c|c|c|c|c|c|}
\hline \multicolumn{14}{|c|}{ City names } \\
\hline Jingjiang & $\mathrm{JJ}(1)$ & Daan & DA & Zitong & $\mathrm{ZT}$ & Muchuan & $\mathrm{MC}$ & Jiangan & JA & Yinjing & $\mathrm{YJ}(1)$ & Jiangjin & $\mathrm{JJ}(3)$ \\
\hline Qingyang & QY & Yantan & YT & Santai & ST & Ebianyi & EBY & Changning & $\mathrm{CL}$ & Hanyuan & HY & Hechuan & $\mathrm{HC}$ \\
\hline Jinniu & $\mathrm{JN}$ & Rongxian & $\mathrm{RX}$ & Yanting & YT & Mabianyi & MBY & Gaoxian & GX(1) & Shimian & SM & Yongchuan & $\mathrm{YC}$ \\
\hline Wuhou & WH & Fushun & FS & Chuanshan & $\mathrm{CS}$ & Shunqing & SQ & Gongxian & GX(2) & Lushan & LS & Nanchuan & $\mathrm{NC}$ \\
\hline Chenghua & $\mathrm{CH}$ & Jiangyang & JY & Anjv & $\mathrm{AJ}$ & Gaoping & GP & Junlian & $\mathrm{JL}$ & Yanjiang & $\mathrm{YJ}(2)$ & Zuanjiang & $\mathrm{ZJ}$ \\
\hline Longquanyi & LQY & Naxi & $\mathrm{NX}$ & Pengxi & PX & Jialing & $J L$ & Xingwen & XW & Jianyang & $J Y$ & Dazu & $\mathrm{DZ}$ \\
\hline Qingbaijiang & QBJ & Longmatan & LMT & Shehong & $\mathrm{SH}$ & Nanbu & NB & Pingshan & $\mathrm{PS}(2)$ & Anyue & AY & Bishan & $\mathrm{BS}$ \\
\hline Xindu & XD & Luxian & LX & Daying & DY(2) & Yingshan & YS & Guangan & GA & Lezhi & $\mathrm{LZ}$ & Tongliang & $\mathrm{TL}$ \\
\hline Wenjiang & WJ & Hejiang & HJ & Neijiangshizhong & NJSZ & Pengan & $\mathrm{PA}$ & Qianfeng & $\mathrm{QF}$ & Yvzhong & $\mathrm{YZ}$ & Tongnan & $\mathrm{TN}$ \\
\hline Dujiangyan & DJY & Xvyong & $X Y$ & Dongxing & DX & Yilong & YL & Huaying & HY & Wanzhou & WZ & Rongchang & $\mathrm{RC}$ \\
\hline Pengzhou & $\mathrm{PZ}$ & Gulin & GL & Zizhong & $\mathrm{ZZ}$ & Xichong & $\mathrm{XC}$ & Yuechi & $\mathrm{CY}$ & Qianjiang & QJ & Liangping & LP \\
\hline Qionglai & QL & Jingyang & JY & Weiyuan & WY & Langzhong & $\mathrm{LZ}$ & Wusheng & WS & Fuling & FL & Fengdu & FD \\
\hline Chongzhou & $\mathrm{CZ}$ & Guanghan & $\mathrm{GH}$ & Longchang & $\mathrm{LC}$ & Pengshan & $\mathrm{PS}(1)$ & Linshui & LS & Dadukou & DDK & Dianjiang & DJ \\
\hline Jintang & JT & Shifang & SF & Leshanshizhong & LSSZ & Dongpo & DP & Tongchuan & $\mathrm{TC}$ & Jiangbei & JB & Zhongxian & $\mathrm{ZX}$ \\
\hline Shuangliu & SL & Mianzhu & $\mathrm{MZ}$ & Wutongqiao & WTQ & Qingshen & QS & Dazhou & $\mathrm{DZ}(1)$ & Shapingba & SPB & Kaixian & $\mathrm{KX}$ \\
\hline pidu & PD & zhongjiang & $\mathrm{ZJ}$ & Shawan & SW & Renshou & $\mathrm{RS}$ & Xuanhan & $\mathrm{XH}$ & Jiulongpo & JLP & Yunyang & YY \\
\hline Dayi & $\mathrm{DY}(1)$ & Luojiang & LJ & Jinkouhe & JKH & Danling & $\mathrm{DL}$ & Kaijiang & $\mathrm{KJ}$ & Nanan & NA & & \\
\hline Pujiang & PJ & Fucheng & $\mathrm{FC}$ & Emeishan & EMS & Hongya & HY & Dazhu & $\mathrm{DZ}(2)$ & Beibei & BB & & \\
\hline Xinjin & $\mathrm{XJ}$ & Youxian & YX & Qianwei & QW & Cuiping & $\mathrm{CP}$ & Qvxian & QX & Yvbei & YB & & \\
\hline Ziliujing & ZLJ & Jiangyou & JY & Jingyan & JY & Nanxi & NX & Yvcheng & $\mathrm{YC}$ & Banan & $\mathrm{BN}$ & & \\
\hline Gongjing & GJ & Anxian & $\mathrm{AX}$ & Jiajiang & $\mathrm{JJ}(2)$ & Yibin & YB & Mingshan & MS & Changshou & $\mathrm{CS}$ & & \\
\hline
\end{tabular}


Table 3 Raw data of Chengdu-Chongqing area

\begin{tabular}{|c|c|c|c|c|c|c|c|c|c|c|c|c|c|c|c|c|}
\hline & $\mathrm{P} 1$ & $\mathrm{P} 2$ & $\mathrm{P} 3$ & $\mathrm{P} 4$ & S1 & S2 & S3 & $\mathrm{S} 4$ & $\mathrm{R} 1$ & $\mathrm{R} 2$ & R3 & $\mathrm{R} 4$ & U1 & $\mathrm{U} 2$ & U3 & $\mathrm{U} 4$ \\
\hline $\mathrm{JJ}(1)$ & 163.689 & 0.000 & 275.481 & 0.375 & 1133.868 & 0.560 & 15.927 & 6.31 & $95.00 \%$ & 10889.881 & 2504.673 & $541.026 \%$ & 125932.721 & 8233 & 0.450 & 0.396 \\
\hline QY & 9.545 & 0.000 & 275.495 & 0.520 & 750.520 & 0.610 & 14.784 & 6.35 & $95.00 \%$ & 11437.321 & 2630.584 & $138.095 \%$ & 131535.909 & 9822 & 0.405 & 0.316 \\
\hline $\mathrm{JN}$ & 12.833 & 0.000 & 275.492 & 0.627 & 1486.483 & 0.990 & 17.658 & 6.59 & $95.00 \%$ & 13358.967 & 3072.562 & $392.500 \%$ & 81052.852 & 6990 & 0.426 & 0.509 \\
\hline WH & 0.426 & 0.000 & 275.491 & 0.808 & 763.460 & 1.120 & 23.839 & 6.86 & $96.00 \%$ & 13705.437 & 3152.251 & $-19.231 \%$ & 65177.943 & 8755 & 0.450 & 0.407 \\
\hline $\mathrm{CH}$ & 17.472 & 0.000 & 275.493 & 0.623 & 332.166 & 0.990 & 20.218 & 6.51 & $94.00 \%$ & 11406.112 & 2623.406 & $166.452 \%$ & 64185.954 & 6623 & 0.417 & 0.506 \\
\hline LQY & 541.969 & 71.076 & 351.035 & 2.804 & 8159.000 & 1.730 & 225.847 & 5.54 & $80.00 \%$ & 16636.417 & 3826.376 & $45.109 \%$ & 18023.968 & 1147 & 0.387 & 1.988 \\
\hline QBJ & 388.847 & 4.077 & 773.488 & 0.938 & 32153.335 & 1.290 & 123.895 & 6.41 & $95.10 \%$ & 6776.090 & 1558.501 & $1.166 \%$ & 8924.963 & 1101 & 0.376 & 2.296 \\
\hline $\mathrm{XD}$ & 498.750 & 2.220 & 535.768 & 1.361 & 20500.000 & 1.940 & 102.176 & 7.29 & $94.00 \%$ & 12801.952 & 2944.449 & $2.225 \%$ & 11749.395 & 1464 & 0.508 & 2.727 \\
\hline WJ & 880.134 & 1.145 & 481.539 & 0.792 & 13794.190 & 1.370 & 73.223 & 6.67 & $91.00 \%$ & 8206.068 & 1887.396 & $7.984 \%$ & 14187.623 & 1484 & 0.419 & 2.044 \\
\hline DJY & 121.373 & 28.626 & 523.315 & 0.430 & 41813.335 & 9.790 & 720.089 & 4.74 & $90.00 \%$ & 7777.545 & 1788.835 & $-3.690 \%$ & 2279.609 & 513 & 0.316 & 2.483 \\
\hline $\mathrm{PZ}$ & 316.023 & 5.793 & 580.345 & 0.926 & 34200.000 & 9.580 & 648.118 & 6.02 & $86.83 \%$ & 9759.000 & 2244.570 & $80.923 \%$ & 2347.289 & 569 & 0.366 & 3.500 \\
\hline QL & 152.358 & 23.938 & 608.866 & 0.500 & 52300.000 & 8.330 & 662.337 & 5.30 & $87.70 \%$ & 7428.833 & 1708.632 & $0.069 \%$ & 1482.982 & 478 & 0.371 & 4.027 \\
\hline $\mathrm{CZ}$ & 218.382 & 7.895 & 598.281 & 0.506 & 39100.000 & 7.010 & 445.074 & 6.22 & $70.00 \%$ & 7703.896 & 1771.896 & $7.476 \%$ & 2076.172 & 615 & 0.405 & 3.901 \\
\hline JT & 373.779 & 6.219 & 346.275 & 0.595 & 4080.000 & 3.850 & 420.206 & 5.39 & $87.00 \%$ & 9113.796 & 2096.173 & $-9.835 \%$ & 2466.240 & 772 & 0.440 & 3.629 \\
\hline SL & 373.967 & 3.445 & 289.380 & 1.545 & 38116.030 & 2.260 & 222.037 & 6.92 & $95.54 \%$ & 23884.015 & 5493.324 & $19.212 \%$ & 8123.699 & 959 & 0.416 & 3.387 \\
\hline PD & 742.325 & 1.757 & 507.161 & 0.965 & 19980.000 & 2.070 & 72.367 & 7.09 & $91.50 \%$ & 11489.376 & 2642.557 & $-19.027 \%$ & 9747.549 & 1260 & 0.430 & 2.807 \\
\hline $\mathrm{DY}(1)$ & 134.590 & 7.651 & 440.807 & 0.394 & 21582.000 & 8.010 & 712.620 & 5.29 & $89.00 \%$ & 6347.890 & 1460.015 & $-9.842 \%$ & 1425.271 & 399 & 0.423 & 4.722 \\
\hline PJ & 247.493 & 0.921 & 687.100 & 0.252 & 24200.000 & 3.340 & 302.180 & 5.16 & $85.30 \%$ & 4161.240 & 957.085 & $12.357 \%$ & 1826.329 & 461 & 0.380 & 3.942 \\
\hline $\mathrm{XJ}$ & 354.736 & 7.024 & 566.214 & 0.531 & 14831.000 & 1.490 & 80.802 & 6.37 & $89.00 \%$ & 6541.528 & 1504.551 & $4.560 \%$ & 6996.401 & 949 & 0.415 & 3.293 \\
\hline ZLJ & 205.208 & 28.760 & 226.830 & 0.740 & 9122.000 & 0.426 & 48.233 & 6.40 & $98.00 \%$ & 691.000 & 283.310 & $5.707 \%$ & 19304.377 & 2390 & 0.380 & 0.979 \\
\hline GJ & 300.207 & 12.446 & 240.534 & 1.100 & 32784.000 & 1.055 & 123.000 & 7.21 & $90.00 \%$ & 979.000 & 401.390 & $-13.278 \%$ & 2950.034 & 719 & 0.332 & 3.598 \\
\hline DA & 249.948 & 20.369 & 297.937 & 0.920 & 32705.000 & 1.062 & 99.849 & 6.24 & $88.80 \%$ & 1499.000 & 614.590 & $-11.798 \%$ & 4911.461 & 1126 & 0.488 & 3.882 \\
\hline
\end{tabular}




\begin{tabular}{|c|c|c|c|c|c|c|c|c|c|c|c|c|c|c|c|c|}
\hline $\mathrm{YT}$ & 276.350 & 38.249 & 214.481 & 0.750 & 44656.000 & 1.273 & 111.622 & 6.46 & $88.50 \%$ & 2857.000 & 1171.370 & $-16.539 \%$ & 2557.885 & 833 & 0.389 & 4.719 \\
\hline $\mathrm{RX}$ & 219.486 & 35.693 & 362.274 & 3.440 & 100807.000 & 4.983 & 656.445 & 5.71 & $85.60 \%$ & 7815.000 & 3204.150 & $-1.900 \%$ & 1159.665 & 427 & 0.097 & 1.553 \\
\hline FS & 226.698 & 42.071 & 251.826 & 1.520 & 91395.000 & 3.494 & 472.384 & 5.74 & $82.00 \%$ & 9032.000 & 3703.120 & $-18.544 \%$ & 1652.651 & 807 & 0.171 & 1.790 \\
\hline JY & 268.755 & 19.682 & 244.208 & 1.784 & 27742.300 & 3.626 & 247.065 & 3.98 & $90.19 \%$ & 2655.000 & 1008.900 & $-0.464 \%$ & 6156.242 & 934 & 0.399 & 3.601 \\
\hline NX & 152.790 & 15.788 & 244.208 & 2.571 & 29292.900 & 6.380 & 628.261 & 7.45 & $90.19 \%$ & 4387.000 & 1667.060 & $-0.383 \%$ & 1079.479 & 401 & 0.399 & 6.695 \\
\hline LMT & 216.882 & 19.476 & 244.208 & 5.592 & 10940.001 & 1.858 & 95.209 & 4.20 & $79.00 \%$ & 4987.000 & 1895.060 & $-6.982 \%$ & 5712.049 & 1081 & 0.399 & 3.439 \\
\hline LX & 255.103 & 11.441 & 244.208 & 3.442 & 74500.000 & 8.722 & 623.916 & 4.81 & $90.19 \%$ & 5919.000 & 2249.220 & $-17.900 \%$ & 1626.503 & 566 & 0.380 & 10.919 \\
\hline HJ & 125.920 & 9.221 & 244.208 & 1.619 & 81033.337 & 13.954 & 1328.019 & 3.87 & $90.19 \%$ & 7362.000 & 2797.560 & $-8.627 \%$ & 669.859 & 294 & 0.340 & 14.482 \\
\hline$X Y$ & 58.510 & 9.684 & 244.208 & 0.794 & 83640.004 & 16.176 & 1641.576 & 6.78 & $83.00 \%$ & 14563.000 & 5533.940 & $-5.029 \%$ & 337.098 & 195 & 0.275 & 20.253 \\
\hline GL & 57.957 & 5.651 & 244.208 & 2.462 & 62695.500 & 13.775 & 1605.265 & 3.60 & $85.00 \%$ & 9251.000 & 3515.380 & $-5.590 \%$ & 402.118 & 221 & 0.343 & 28.411 \\
\hline SY & 312.703 & 3.990 & 540.396 & 3.559 & 55274.000 & 2.415 & 138.659 & 4.30 & $91.50 \%$ & 3000.000 & 780.000 & $8.285 \%$ & 7037.865 & 1068 & 0.401 & 8.146 \\
\hline $\mathrm{GH}$ & 470.389 & 3.494 & 572.774 & 3.402 & 72612.000 & 2.038 & 91.630 & 4.70 & $67.90 \%$ & 3624.000 & 942.240 & $6.482 \%$ & 5903.765 & 1106 & 0.408 & 4.087 \\
\hline SF & 309.432 & 5.261 & 584.424 & 1.927 & 47799.000 & 4.310 & 306.792 & 4.80 & $87.00 \%$ & 6053.000 & 1573.780 & $-2.442 \%$ & 2850.472 & 530 & 0.460 & 3.679 \\
\hline $\mathrm{MZ}$ & 183.276 & 8.175 & 592.855 & 2.305 & 57972.000 & 7.000 & 635.470 & 4.20 & $91.60 \%$ & 4121.000 & 1071.460 & $9.471 \%$ & 1728.482 & 404 & 0.394 & 2.423 \\
\hline ZJ & 234.127 & 23.713 & 275.645 & 1.878 & 180815.000 & 6.530 & 893.362 & 4.60 & $64.10 \%$ & 3244.000 & 843.440 & $7.945 \%$ & 1308.608 & 642 & 0.352 & 2.307 \\
\hline $\mathrm{LJ}$ & 274.048 & 7.085 & 530.730 & 0.991 & 37610.000 & 1.808 & 177.670 & 3.50 & $63.60 \%$ & 2524.000 & 656.240 & $0.518 \%$ & 1964.458 & 557 & 0.319 & 2.125 \\
\hline $\mathrm{FC}$ & 346.222 & 19.163 & 373.274 & 0.329 & 33041.000 & 2.473 & 143.106 & 4.18 & $92.74 \%$ & 2113.000 & 52.163 & $16.068 \%$ & 11316.055 & 500 & 0.387 & 5.738 \\
\hline YX & 224.911 & 12.905 & 346.595 & 0.230 & 56514.000 & 1.488 & 304.731 & 4.18 & $92.74 \%$ & 3257.000 & 80.404 & $-0.979 \%$ & 1853.274 & 209 & 0.387 & 12.943 \\
\hline JY & 136.197 & 6.635 & 585.117 & 2.437 & 86400.000 & 11.173 & 1281.191 & 4.00 & $88.01 \%$ & 7998.000 & 197.443 & $-47.278 \%$ & 1186.479 & 115 & 0.420 & 19.391 \\
\hline $\mathrm{AX}$ & 196.051 & 9.824 & 409.439 & 2.784 & 64703.000 & 12.762 & 422.376 & 4.23 & $95.86 \%$ & 5665.000 & 139.849 & $-64.835 \%$ & 929.102 & 162 & 0.360 & 14.240 \\
\hline $\mathrm{ZT}$ & 151.495 & 10.915 & 401.022 & 0.305 & 68468.000 & 5.666 & 607.890 & 4.49 & $65.75 \%$ & 4597.000 & 113.484 & $-10.421 \%$ & 590.753 & 102 & 0.360 & 20.413 \\
\hline ST & 229.343 & 11.672 & 284.793 & 0.514 & 196007.000 & 6.302 & 1013.224 & 3.86 & $69.94 \%$ & 7310.000 & 180.459 & $691.388 \%$ & 771.608 & 210 & 0.400 & 11.805 \\
\hline $\mathrm{YT}$ & 171.328 & 11.256 & 234.313 & 0.157 & 82456.000 & 2.039 & 927.763 & 4.44 & $47.06 \%$ & 3975.000 & 98.129 & $27.624 \%$ & 524.022 & 151 & 0.405 & 11.703 \\
\hline $\mathrm{CS}$ & 206.451 & 15.901 & 275.525 & 1.290 & 60466.000 & 1.724 & 238.388 & 3.85 & $100.00 \%$ & 5347.000 & 3422.080 & $41.681 \%$ & 4191.605 & 1167 & 0.356 & 32.402 \\
\hline
\end{tabular}




\begin{tabular}{|c|c|c|c|c|c|c|c|c|c|c|c|c|c|c|c|c|}
\hline $\mathrm{AJ}$ & 273.827 & 20.482 & 211.173 & 1.010 & 132570.000 & 3.423 & 451.874 & 3.59 & $31.58 \%$ & 7376.000 & 4720.640 & $1.663 \%$ & 916.056 & 637 & 0.051 & 0.673 \\
\hline PX & 204.197 & 16.807 & 152.381 & 1.210 & 120243.000 & 2.903 & 501.651 & 3.49 & $54.03 \%$ & 3641.000 & 2330.240 & $1.854 \%$ & 957.630 & 570 & 0.363 & 8.055 \\
\hline $\mathrm{SH}$ & 185.898 & 14.162 & 258.129 & 1.660 & 129543.000 & 3.919 & 625.328 & 3.51 & $78.32 \%$ & 4652.000 & 2977.280 & $-16.237 \%$ & 1956.204 & 669 & 0.286 & 12.048 \\
\hline DY(2) & 155.675 & 20.181 & 315.816 & 1.560 & 80277.000 & 1.399 & 243.247 & 3.84 & $87.69 \%$ & 4010.000 & 2566.400 & $-7.201 \%$ & 1853.424 & 789 & 0.297 & 9.656 \\
\hline NJSZ & 273.614 & 7.935 & 248.992 & 0.780 & 35917.000 & 0.757 & 104.666 & 4.02 & $89.01 \%$ & 1806.000 & 38.214 & $-1.775 \%$ & 5571.559 & 2307 & 0.354 & 9.260 \\
\hline DX & 320.411 & 25.897 & 175.527 & 1.030 & 105461.000 & 2.647 & 312.736 & 4.58 & $89.08 \%$ & 1884.000 & 39.865 & $-0.954 \%$ & 1855.712 & 1054 & 0.367 & 9.800 \\
\hline $\mathrm{ZZ}$ & 300.681 & 23.049 & 174.836 & 2.460 & 147882.000 & 3.533 & 606.539 & 4.26 & $86.67 \%$ & 7215.000 & 152.666 & $103.928 \%$ & 1361.730 & 2175 & 0.242 & 6.250 \\
\hline WY & 270.113 & 16.453 & 269.953 & 3.500 & 95018.000 & 2.886 & 517.534 & 4.23 & $79.73 \%$ & 7416.000 & 156.919 & $-66.193 \%$ & 2284.179 & 3557 & 0.322 & 8.240 \\
\hline $\mathrm{LC}$ & 256.769 & 21.106 & 217.870 & 1.270 & 65142.000 & 1.990 & 243.804 & 5.05 & $97.01 \%$ & 3498.000 & 74.016 & $-3.598 \%$ & 2933.541 & 3772 & 0.390 & 10.850 \\
\hline LSSZ & 170.110 & 12.671 & 423.189 & 0.815 & 34651.898 & 6.220 & 306.175 & 4.70 & $80.20 \%$ & 2583.000 & 710.758 & $6.405 \%$ & 3412.069 & 737 & 0.371 & 6.734 \\
\hline WTQ & 190.475 & 6.787 & 536.715 & 2.549 & 27812.918 & 3.400 & 166.145 & 4.90 & $75.46 \%$ & 2314.000 & 636.738 & $-12.914 \%$ & 2938.604 & 666 & 0.268 & 2.080 \\
\hline SW & 91.150 & 17.993 & 568.577 & 1.569 & 14357.895 & 5.020 & 339.178 & 5.50 & $75.46 \%$ & 6905.000 & 1900.034 & $-9.588 \%$ & 2868.653 & 302 & 0.295 & 2.161 \\
\hline JKH & 23.525 & 7.575 & 342.592 & 2.524 & 3548.308 & 3.750 & 329.259 & 5.80 & $90.00 \%$ & 2555.000 & 703.054 & $-3.639 \%$ & 533.833 & 85 & 0.091 & 1.539 \\
\hline EMS & 110.993 & 7.440 & 366.585 & 3.074 & 31511.814 & 12.310 & 735.999 & 4.00 & $80.20 \%$ & 7819.000 & 2151.537 & $1.440 \%$ & 1786.913 & 365 & 0.446 & 5.483 \\
\hline QW & 130.025 & 11.532 & 347.334 & 2.419 & 79011.473 & 10.240 & 600.087 & 4.80 & $87.00 \%$ & 6560.000 & 1805.101 & $-4.182 \%$ & 976.133 & 416 & 0.330 & 2.377 \\
\hline JY & 151.076 & 8.401 & 310.481 & 2.869 & 70636.825 & 3.550 & 232.008 & 4.40 & $95.00 \%$ & 4748.000 & 1306.497 & $4.387 \%$ & 961.917 & 489 & 0.181 & 0.849 \\
\hline $\mathrm{JJ}(2)$ & 220.179 & 18.221 & 623.035 & 2.652 & 36214.737 & 6.160 & 276.768 & 5.50 & $75.46 \%$ & 2395.000 & 659.027 & $-19.945 \%$ & 1686.546 & 468 & 0.185 & 2.115 \\
\hline $\mathrm{MC}$ & 81.214 & 23.087 & 198.366 & 1.795 & 25502.050 & 13.490 & 1001.203 & 4.20 & $96.00 \%$ & 5790.000 & 1593.221 & $-14.146 \%$ & 387.811 & 182 & 0.352 & 2.059 \\
\hline EBY & 9.154 & 3.645 & 178.899 & 1.784 & 12990.492 & 18.170 & 1812.940 & 5.10 & $57.50 \%$ & 11594.000 & 3190.295 & $4.437 \%$ & 148.447 & 62 & 0.106 & 0.398 \\
\hline MBY & 28.450 & 5.402 & 178.106 & 1.696 & 21285.590 & 21.780 & 1252.437 & 4.60 & $82.80 \%$ & 8585.000 & 2362.315 & $-23.665 \%$ & 139.884 & 94 & 0.174 & 0.970 \\
\hline SQ & 292.589 & 8.204 & 193.243 & 0.190 & 26620.000 & 1.516 & 139.551 & 4.39 & $86.50 \%$ & 3215.000 & 278.691 & $-4.123 \%$ & 391.799 & 1311 & 0.431 & 12.100 \\
\hline GP & 241.733 & 8.306 & 165.574 & 0.230 & 35494.000 & 1.944 & 307.892 & 5.00 & $80.00 \%$ & 3909.000 & 338.850 & $-8.729 \%$ & 323.174 & 749 & 0.431 & 12.100 \\
\hline $\mathrm{JL}$ & 198.375 & 19.755 & 157.322 & 0.170 & 66552.000 & 4.139 & 349.216 & 3.80 & $86.50 \%$ & 3656.000 & 316.919 & $-1.074 \%$ & 282.485 & 523 & 0.431 & 12.100 \\
\hline NB & 177.530 & 17.906 & 182.370 & 0.160 & 107293.000 & 6.195 & 1065.940 & 4.60 & $83.00 \%$ & 5026.000 & 435.676 & $0.000 \%$ & 241.046 & 419 & 0.378 & 8.700 \\
\hline
\end{tabular}




\begin{tabular}{|c|c|c|c|c|c|c|c|c|c|c|c|c|c|c|c|c|}
\hline YS & 173.972 & 4.465 & 156.003 & 0.150 & 64655.000 & 4.558 & 576.665 & 3.95 & $83.30 \%$ & 5055.000 & 438.190 & $-8.609 \%$ & 230.546 & 454 & 0.376 & 8.500 \\
\hline PA & 208.244 & 6.243 & 148.234 & 0.160 & 59987.000 & 3.949 & 422.060 & 4.24 & $76.30 \%$ & 5180.000 & 449.026 & $-4.978 \%$ & 269.860 & 428 & 0.366 & 8.700 \\
\hline YL & 202.644 & 8.108 & 128.381 & 0.100 & 83714.000 & 4.164 & 625.337 & 4.74 & $83.00 \%$ & 7808.000 & 676.833 & $52.533 \%$ & 305.240 & 524 & 0.369 & 9.000 \\
\hline $\mathrm{XC}$ & 212.248 & 6.464 & 172.304 & 0.080 & 73243.000 & 3.303 & 498.150 & 3.80 & $85.10 \%$ & 4671.000 & 404.903 & $1.496 \%$ & 270.777 & 478 & 0.374 & 9.000 \\
\hline $\mathrm{LZ}$ & 161.034 & 16.034 & 184.777 & 0.140 & 69296.000 & 8.200 & 649.500 & 4.67 & $85.92 \%$ & 8218.000 & 712.374 & $0.903 \%$ & 231.606 & 389 & 0.427 & 10.500 \\
\hline $\operatorname{PS}(1)$ & 296.215 & 12.526 & 420.591 & 1.643 & 16848.895 & 5.407 & 512.316 & 4.77 & $84.60 \%$ & 8650.864 & 1730.173 & $-7.966 \%$ & 2644.596 & 665 & 0.397 & 20.055 \\
\hline DP & 31.696 & 2.224 & 486.191 & 1.609 & 5439.419 & 1.800 & 952.181 & 5.00 & $45.00 \%$ & 5870.003 & 1174.001 & $-0.977 \%$ & 473.249 & 711 & 0.239 & 11.765 \\
\hline QS & 162.245 & 14.532 & 439.403 & 0.523 & 3609.183 & 1.876 & 178.833 & 3.81 & $85.00 \%$ & 3448.648 & 689.730 & $45.399 \%$ & 1678.106 & 510 & 0.364 & 15.582 \\
\hline $\mathrm{RS}$ & 1229.463 & 53.443 & 296.004 & 2.333 & 30730.694 & 9.699 & 170.175 & 4.71 & $85.00 \%$ & 13598.890 & 2719.778 & $-3.606 \%$ & 7273.186 & 604 & 0.328 & 5.855 \\
\hline DL & 192.244 & 12.578 & 253.073 & 0.289 & 3949.701 & 2.458 & 268.065 & 4.41 & $87.00 \%$ & 2938.093 & 587.619 & $8.557 \%$ & 1112.076 & 363 & 0.443 & 17.039 \\
\hline $\mathrm{HY}$ & 56.737 & 11.019 & 369.411 & 0.395 & 4884.872 & 22.431 & 1347.580 & 4.35 & $84.60 \%$ & 4664.295 & 932.859 & $8.659 \%$ & 527.211 & 185 & 0.420 & 13.375 \\
\hline $\mathrm{CP}$ & 163.854 & 3.568 & 335.235 & 0.153 & 48335.000 & 5.977 & 464.841 & 4.11 & $78.00 \%$ & 4022.000 & 872.636 & $11.434 \%$ & 4524.038 & 754 & 0.382 & 2.986 \\
\hline NX & 254.072 & 15.632 & 328.540 & 0.203 & 52231.000 & 2.513 & 310.957 & 4.65 & $94.00 \%$ & 4226.000 & 916.897 & $5.263 \%$ & 1529.815 & 484 & 0.382 & 4.405 \\
\hline YB & 113.105 & 5.300 & 286.525 & 0.165 & 113075.000 & 17.013 & 1186.878 & 5.59 & $71.94 \%$ & 7708.000 & 1672.371 & $0.850 \%$ & 739.153 & 263 & 0.360 & 8.177 \\
\hline $\mathrm{JA}$ & 202.639 & 16.507 & 254.076 & 0.364 & 47401.000 & 4.868 & 326.668 & 5.61 & $89.00 \%$ & 4086.000 & 886.522 & $122.652 \%$ & 1371.115 & 467 & 0.400 & 5.441 \\
\hline $\mathrm{CL}$ & 155.889 & 48.414 & 267.929 & 1.635 & 48121.000 & 6.187 & 564.732 & 5.18 & $85.84 \%$ & 5185.000 & 1124.967 & $123.645 \%$ & 1096.626 & 346 & 0.415 & 5.197 \\
\hline GX(1) & 117.647 & 7.128 & 216.061 & 0.610 & 56895.000 & 7.206 & 605.220 & 4.63 & $75.00 \%$ & 6417.000 & 1392.269 & $-0.312 \%$ & 855.486 & 314 & 0.382 & 6.595 \\
\hline GX(2) & 105.547 & 7.121 & 224.325 & 1.025 & 46824.000 & 7.737 & 579.714 & 5.66 & $85.00 \%$ & 4118.000 & 893.465 & $6.107 \%$ & 1072.583 & 327 & 0.382 & 5.774 \\
\hline $\mathrm{JL}$ & 110.127 & 11.128 & 354.905 & 0.558 & 42452.000 & 12.769 & 612.677 & 4.10 & $80.75 \%$ & 25697.000 & 5575.367 & $-6.001 \%$ & 882.810 & 265 & 0.345 & 6.677 \\
\hline XW & 97.368 & 10.767 & 225.842 & 0.468 & 47997.000 & 9.793 & 662.814 & 5.11 & $100.00 \%$ & 6538.000 & 1418.522 & $79.263 \%$ & 585.565 & 280 & 0.390 & 7.237 \\
\hline $\operatorname{PS}(2)$ & 85.639 & 13.417 & 260.359 & 0.684 & 40673.000 & 12.577 & 791.104 & 5.54 & $85.00 \%$ & 5624.000 & 1220.215 & $-30.766 \%$ & 266.369 & 170 & 0.397 & 11.051 \\
\hline GA & 215.910 & 18.111 & 174.806 & 0.741 & 79225.000 & 6.496 & 395.703 & 4.70 & $100.00 \%$ & 5892.925 & 1687.532 & $50.799 \%$ & 1409.418 & 599 & 0.420 & 4.313 \\
\hline QF & 250.557 & 20.944 & 316.776 & 3.572 & 33614.000 & 4.897 & 262.657 & 4.70 & $96.55 \%$ & 2631.014 & 753.432 & $2.000 \%$ & 2980.935 & 507 & 0.400 & 3.788 \\
\hline $\mathrm{HK}$ & 178.666 & 17.210 & 262.481 & 2.301 & 29705.000 & 4.480 & 220.712 & 4.92 & $97.10 \%$ & 3733.420 & 1069.124 & $-5.585 \%$ & 2898.766 & 610 & 0.380 & 3.266 \\
\hline
\end{tabular}




\begin{tabular}{|c|c|c|c|c|c|c|c|c|c|c|c|c|c|c|c|c|}
\hline $\mathrm{CY}$ & 226.724 & 8.295 & 155.692 & 1.153 & 130999.000 & 7.406 & 492.604 & 4.54 & $90.00 \%$ & 7076.379 & 2026.433 & $6.122 \%$ & 1278.046 & 533 & 0.320 & 4.011 \\
\hline WS & 292.419 & 13.933 & 183.368 & 1.085 & 91052.000 & 6.534 & 377.438 & 4.00 & $86.20 \%$ & 5721.773 & 1638.520 & $-5.519 \%$ & 1980.137 & 618 & 0.363 & 3.556 \\
\hline LS & 196.820 & 9.918 & 221.167 & 1.051 & 123234.000 & 9.537 & 784.632 & 4.30 & $87.00 \%$ & 6423.130 & 1839.365 & $-4.798 \%$ & 1034.582 & 374 & 0.395 & 6.216 \\
\hline $\mathrm{TC}$ & 209.485 & 11.579 & 160.009 & 2.473 & 53421.000 & 6.483 & 314.352 & 6.38 & $52.86 \%$ & 616.770 & 343.770 & $-44.915 \%$ & 2234.009 & 673 & 0.350 & 3.171 \\
\hline $\mathrm{DZ}(1)$ & 190.632 & 10.537 & 156.221 & 2.457 & 139994.000 & 10.199 & 727.380 & 6.50 & $82.00 \%$ & 12841.286 & 3771.365 & $10.400 \%$ & 1001.725 & 527 & 0.350 & 5.205 \\
\hline $\mathrm{XH}$ & 117.566 & 6.498 & 239.393 & 2.850 & 163316.000 & 15.774 & 2563.200 & 3.62 & $83.05 \%$ & 14360.000 & 4217.397 & $-9.880 \%$ & 525.055 & 304 & 0.322 & 5.343 \\
\hline $\mathrm{KJ}$ & 260.300 & 14.388 & 252.907 & 2.640 & 74177.000 & 7.277 & 381.470 & 3.43 & $85.00 \%$ & 6389.626 & 1876.573 & $-10.344 \%$ & 1011.133 & 573 & 0.361 & 5.214 \\
\hline $\mathrm{DZ}(2)$ & 234.053 & 12.937 & 177.745 & 2.589 & 151682.000 & 10.106 & 838.045 & 4.24 & $84.00 \%$ & 10693.030 & 3140.442 & $-13.406 \%$ & 1265.078 & 529 & 0.330 & 4.609 \\
\hline QX & 257.335 & 14.224 & 128.045 & 2.834 & 159745.000 & 9.256 & 726.480 & 3.61 & $52.86 \%$ & 12395.552 & 3640.457 & $-7.095 \%$ & 1079.323 & 677 & 0.372 & 4.252 \\
\hline $\mathrm{YC}$ & 127.450 & 25.476 & 108.023 & 0.290 & 19438.000 & 11.587 & 666.395 & 4.37 & $85.15 \%$ & 4425.400 & 1060.196 & $7.112 \%$ & 1317.498 & 323 & 0.426 & 24.563 \\
\hline MS & 245.123 & 48.997 & 98.566 & 1.470 & 28659.000 & 7.696 & 296.640 & 5.10 & $85.15 \%$ & 3107.360 & 744.432 & $-2.206 \%$ & 989.644 & 451 & 0.361 & 12.673 \\
\hline $\mathrm{YJ}(1)$ & 31.651 & 6.327 & 297.850 & 1.400 & 18755.000 & 13.141 & 1362.781 & 3.70 & $100.00 \%$ & 5808.400 & 1391.522 & $-4.625 \%$ & 345.132 & 84 & 0.362 & 12.011 \\
\hline HY & 51.423 & 10.279 & 148.182 & 0.640 & 44231.000 & 13.794 & 1224.895 & 3.60 & $85.00 \%$ & 3129.860 & 749.822 & $-5.353 \%$ & 285.914 & 145 & 0.381 & 3.648 \\
\hline SM & 17.957 & 3.589 & 429.367 & 1.710 & 11691.000 & 16.051 & 1702.505 & 3.20 & $86.00 \%$ & 2797.660 & 670.237 & $46.246 \%$ & 261.292 & 46 & 0.380 & 10.415 \\
\hline LS & 39.279 & 7.851 & 297.170 & 0.580 & 14558.000 & 10.502 & 914.212 & 3.60 & $85.00 \%$ & 5147.260 & 1233.132 & $-24.281 \%$ & 270.949 & 102 & 0.269 & 10.936 \\
\hline $\mathrm{YJ}(2)$ & 267.865 & 21.860 & 22.520 & 0.968 & 186648.000 & 4.250 & 466.846 & 4.00 & $86.58 \%$ & 2901.000 & 751.239 & $2.120 \%$ & 2513.952 & 677 & 0.387 & 15.301 \\
\hline JY & 198.040 & 13.533 & 12.762 & 0.987 & 215909.000 & 5.127 & 836.924 & 4.42 & $85.03 \%$ & 11204.000 & 2901.374 & $8.213 \%$ & 1813.282 & 672 & 0.367 & 6.894 \\
\hline AY & 255.171 & 13.877 & 8.184 & 0.960 & 206029.000 & 5.951 & 1148.545 & 4.01 & $86.00 \%$ & 8278.000 & 2143.661 & $-3.306 \%$ & 1043.200 & 598 & 0.185 & 2.823 \\
\hline $\mathrm{LZ}$ & 145.160 & 12.091 & 9.968 & 0.923 & 127799.000 & 3.923 & 588.327 & 2.00 & $86.58 \%$ & 3335.000 & 863.627 & $-12.160 \%$ & 1250.246 & 588 & 0.411 & 14.530 \\
\hline YZ & 0.000 & 0.000 & 110.808 & 0.101 & 0.000 & 0.103 & 10.670 & 5.56 & $93.50 \%$ & 5306.746 & 3944.896 & $0.000 \%$ & 404122.000 & 27394 & 0.398 & 6.800 \\
\hline WZ & 166.588 & 10.142 & 240.652 & 0.248 & 178657.000 & 16.701 & 1662.519 & 4.68 & $91.00 \%$ & 9154.512 & 6805.225 & $-2.314 \%$ & 2396.206 & 470 & 0.367 & 11.570 \\
\hline QJ & 56.066 & 7.082 & 248.497 & 0.149 & 85128.000 & 13.899 & 1345.120 & 3.82 & $93.70 \%$ & 3910.709 & 2907.119 & $-8.790 \%$ & 843.256 & 194 & 0.435 & 38.000 \\
\hline FL & 166.381 & 10.709 & 437.938 & 0.271 & 180316.000 & 15.746 & 1353.476 & 4.96 & $90.00 \%$ & 9113.616 & 6774.824 & $1.518 \%$ & 2763.753 & 390 & 0.415 & 66.357 \\
\hline DDK & 178.820 & 20.423 & 225.428 & 0.220 & 1683.000 & 0.461 & 41.068 & 5.66 & $91.00 \%$ & 1903.543 & 1415.044 & $128.900 \%$ & 15556.560 & 3240 & 0.440 & 17.300 \\
\hline
\end{tabular}




\begin{tabular}{|c|c|c|c|c|c|c|c|c|c|c|c|c|c|c|c|c|}
\hline JB & 29.731 & 18.934 & 204.017 & 0.024 & 1531.000 & 0.805 & 45.479 & 4.77 & $95.00 \%$ & 7708.766 & 5730.495 & $443.000 \%$ & 31132.400 & 3902 & 0.428 & 21.040 \\
\hline SPB & 146.348 & 2.828 & 186.163 & 0.016 & 7485.000 & 1.431 & 108.955 & 5.46 & $94.50 \%$ & 6724.778 & 4999.024 & $155.389 \%$ & 18028.773 & 2862 & 0.359 & 49.086 \\
\hline JLP & 238.709 & 3.725 & 219.096 & 0.085 & 11130.000 & 1.373 & 175.758 & 4.88 & $97.00 \%$ & 7079.321 & 5262.582 & $45.470 \%$ & 23296.578 & 2790 & 0.427 & 14.840 \\
\hline NA & 215.753 & 5.648 & 211.489 & 0.040 & 2159.000 & 1.330 & 110.221 & 5.16 & $93.67 \%$ & 8068.140 & 5997.644 & $130.949 \%$ & 25888.046 & 3330 & 0.436 & 12.400 \\
\hline $\mathrm{BB}$ & 232.187 & 3.630 & 302.913 & 0.110 & 29674.000 & 3.794 & 367.534 & 4.75 & $87.80 \%$ & 3763.145 & 2797.423 & $-11.546 \%$ & 5699.868 & 1041 & 0.388 & 17.800 \\
\hline YB & 172.612 & 10.217 & 171.239 & 0.017 & 60652.000 & 6.320 & 566.280 & 5.03 & $85.00 \%$ & 7185.974 & 5341.865 & $-8.551 \%$ & 8218.595 & 1104 & 0.455 & 18.000 \\
\hline $\mathrm{BN}$ & 255.914 & 5.617 & 203.111 & 0.047 & 88244.000 & 8.204 & 793.701 & 5.09 & $95.00 \%$ & 4503.391 & 3347.703 & $1.126 \%$ & 3114.874 & 576 & 0.408 & 22.900 \\
\hline $\mathrm{CS}$ & 205.687 & 6.335 & 439.361 & 0.954 & 91069.000 & 5.936 & 642.053 & 5.41 & $91.50 \%$ & 4263.977 & 3169.729 & $-7.908 \%$ & 3021.312 & 580 & 0.439 & 19.950 \\
\hline $\mathrm{JJ}(3)$ & 226.358 & 5.312 & 646.893 & 0.290 & 154519.000 & 16.569 & 1360.187 & 6.15 & $93.50 \%$ & 6948.029 & 5164.983 & $-23.237 \%$ & 1892.209 & 423 & 0.321 & 13.350 \\
\hline $\mathrm{HC}$ & 256.785 & 9.245 & 225.109 & 0.478 & 174296.000 & 9.789 & 489.687 & 5.23 & $91.00 \%$ & 5212.850 & 3875.097 & $-1.801 \%$ & 2032.394 & 587 & 0.421 & 16.110 \\
\hline $\mathrm{YC}$ & 231.832 & 10.622 & 284.765 & 0.167 & 106982.000 & 8.340 & 732.840 & 5.21 & $82.32 \%$ & 5783.494 & 4299.298 & $-11.130 \%$ & 3618.909 & 705 & 0.421 & 23.300 \\
\hline $\mathrm{NC}$ & 123.220 & 8.696 & 321.551 & 0.511 & 106693.000 & 13.590 & 1287.990 & 5.00 & $91.00 \%$ & 3430.411 & 2538.504 & $-5.020 \%$ & 715.796 & 220 & 0.359 & 10.310 \\
\hline $\mathrm{ZJ}$ & 222.491 & 18.458 & 235.103 & 0.712 & 123920.000 & 11.718 & 918.681 & 5.60 & $73.60 \%$ & 5765.875 & 4286.201 & $-26.252 \%$ & 1732.428 & 497 & 0.399 & 10.310 \\
\hline $\mathrm{DZ}$ & 245.859 & 16.330 & 230.210 & 0.079 & 108328.000 & 7.403 & 624.660 & 4.42 & $90.00 \%$ & 5066.640 & 3766.408 & $-7.089 \%$ & 2431.546 & 543 & 0.449 & 14.110 \\
\hline $\mathrm{BS}$ & 161.978 & 4.353 & 168.105 & 0.053 & 55428.000 & 4.103 & 454.536 & 6.16 & $93.67 \%$ & 5134.385 & 3816.767 & $-17.866 \%$ & 4174.248 & 793 & 0.490 & 13.980 \\
\hline $\mathrm{TL}$ & 188.763 & 6.706 & 294.786 & 0.113 & 118202.000 & 6.229 & 647.442 & 4.58 & $97.50 \%$ & 3508.193 & 2607.899 & $-15.472 \%$ & 2299.211 & 537 & 0.424 & 22.670 \\
\hline $\mathrm{TN}$ & 298.138 & 14.352 & 272.529 & 0.075 & 148873.000 & 6.319 & 712.350 & 4.40 & $94.00 \%$ & 3676.162 & 2732.762 & $1.922 \%$ & 1675.300 & 445 & 0.400 & 36.000 \\
\hline $\mathrm{RC}$ & 345.229 & 16.761 & 242.028 & 0.108 & 78423.000 & 3.611 & 372.211 & 5.12 & $93.67 \%$ & 3544.632 & 2634.987 & $8.438 \%$ & 3062.860 & 654 & 0.450 & 11.000 \\
\hline LP & 168.295 & 9.194 & 250.031 & 0.188 & 102579.000 & 7.666 & 832.537 & 4.48 & $80.00 \%$ & 4025.866 & 2992.723 & $-21.217 \%$ & 1280.726 & 345 & 0.380 & 17.170 \\
\hline FD & 70.496 & 8.130 & 215.186 & 1.106 & 112471.000 & 12.513 & 1293.846 & 5.01 & $95.00 \%$ & 3736.051 & 2777.283 & $-15.715 \%$ & 517.718 & 202 & 0.389 & 18.520 \\
\hline DJ & 202.864 & 6.790 & 288.014 & 0.242 & 90951.000 & 6.113 & 652.740 & 4.68 & $89.10 \%$ & 3156.696 & 2346.605 & $45.403 \%$ & 1579.974 & 453 & 0.351 & 10.950 \\
\hline $\mathrm{ZX}$ & 145.896 & 6.047 & 197.168 & 0.724 & 109123.000 & 8.825 & 1100.061 & 3.75 & $98.00 \%$ & 3671.323 & 2729.166 & $-11.286 \%$ & 1016.918 & 328 & 0.398 & 1.941 \\
\hline $\mathrm{KX}$ & 120.377 & 6.160 & 254.414 & 0.291 & 181066.000 & 18.599 & 1882.425 & 4.63 & $90.00 \%$ & 5429.642 & 4036.254 & $-10.552 \%$ & 822.559 & 296 & 0.417 & 12.750 \\
\hline YY & 101.333 & 7.171 & 173.477 & 0.071 & 133818.000 & 16.249 & 1824.500 & 3.79 & $83.00 \%$ & 4676.054 & 3476.057 & $-9.330 \%$ & 514.963 & 250 & 0.411 & 15.000 \\
\hline
\end{tabular}

696 
Table 5 Assessment results of PSRU in Chengdu-Chongqing Economic Circle

\begin{tabular}{|c|c|c|c|c|c|c|c|c|c|c|c|c|c|c|}
\hline & $\mathrm{P}$ & $\mathrm{S}$ & $\mathrm{R}$ & $\mathrm{U}$ & & $\mathrm{P}$ & $\mathrm{S}$ & $\mathrm{R}$ & $\mathrm{U}$ & & $\mathrm{P}$ & $\mathrm{S}$ & $\mathrm{R}$ & $\mathrm{U}$ \\
\hline $\mathrm{JJ}(1)$ & 0.115 & 0.036 & 0.551 & 0.276 & FS & 0.345 & 0.266 & 0.384 & 0.045 & $\mathrm{SH}$ & 0.248 & 0.398 & 0.295 & 0.119 \\
\hline QY & 0.099 & 0.035 & 0.423 & 0.286 & $J Y$ & 0.286 & 0.196 & 0.189 & 0.113 & $\mathrm{DY}(2)$ & 0.272 & 0.246 & 0.283 & 0.111 \\
\hline $\mathrm{JN}$ & 0.107 & 0.036 & 0.556 & 0.224 & NX & 0.303 & 0.187 & 0.243 & 0.118 & NJSZ & 0.181 & 0.155 & 0.124 & 0.142 \\
\hline WH & 0.116 & 0.03 & 0.421 & 0.237 & LMT & 0.52 & 0.128 & 0.242 & 0.114 & DX & 0.251 & 0.287 & 0.125 & 0.132 \\
\hline $\mathrm{CH}$ & 0.107 & 0.036 & 0.431 & 0.206 & LX & 0.359 & 0.347 & 0.285 & 0.135 & $\mathrm{ZZ}$ & 0.329 & 0.398 & 0.217 & 0.097 \\
\hline LQY & 0.607 & 0.103 & 0.486 & 0.114 & HJ & 0.214 & 0.521 & 0.333 & 0.138 & WY & 0.390 & 0.306 & 0.149 & 0.141 \\
\hline QBJ & 0.325 & 0.099 & 0.269 & 0.105 & $X Y$ & 0.152 & 0.514 & 0.548 & 0.148 & LC & 0.249 & 0.202 & 0.154 & 0.172 \\
\hline $\mathrm{XD}$ & 0.304 & 0.067 & 0.405 & 0.145 & GL & 0.244 & 0.528 & 0.385 & 0.202 & LSSZ & 0.226 & 0.227 & 0.158 & 0.117 \\
\hline WJ & 0.312 & 0.062 & 0.297 & 0.122 & SY & 0.422 & 0.201 & 0.184 & 0.137 & WTQ & 0.347 & 0.162 & 0.137 & 0.069 \\
\hline DJY & 0.271 & 0.326 & 0.282 & 0.081 & $\mathrm{GH}$ & 0.444 & 0.206 & 0.162 & 0.119 & SW & 0.317 & 0.166 & 0.255 & 0.072 \\
\hline $\mathrm{PZ}$ & 0.271 & 0.273 & 0.352 & 0.098 & $\mathrm{SF}$ & 0.333 & 0.219 & 0.248 & 0.121 & JKH & 0.274 & 0.126 & 0.169 & 0.016 \\
\hline QL & 0.29 & 0.302 & 0.272 & 0.1 & $\mathrm{MZ}$ & 0.349 & 0.318 & 0.212 & 0.098 & EMS & 0.328 & 0.363 & 0.289 & 0.124 \\
\hline $\mathrm{CZ}$ & 0.24 & 0.221 & 0.253 & 0.11 & ZJ & 0.308 & 0.506 & 0.148 & 0.089 & QW & 0.300 & 0.371 & 0.266 & 0.081 \\
\hline $\mathrm{JT}$ & 0.203 & 0.148 & 0.306 & 0.119 & $\mathrm{LJ}$ & 0.261 & 0.191 & 0.127 & 0.08 & $J Y$ & 0.311 & 0.245 & 0.235 & 0.039 \\
\hline $\mathrm{SL}$ & 0.24 & 0.118 & 0.666 & 0.118 & $\mathrm{FC}$ & 0.235 & 0.173 & 0.139 & 0.119 & $\mathrm{JJ}(2)$ & 0.421 & 0.206 & 0.137 & 0.046 \\
\hline PD & 0.309 & 0.069 & 0.364 & 0.123 & YX & 0.18 & 0.211 & 0.146 & 0.142 & $\mathrm{MC}$ & 0.257 & 0.393 & 0.257 & 0.082 \\
\hline $\mathrm{DY}(1)$ & 0.18 & 0.26 & 0.246 & 0.115 & JY & 0.343 & 0.485 & 0.177 & 0.178 & EBY & 0.17 & 0.498 & 0.351 & 0.014 \\
\hline PJ & 0.225 & 0.164 & 0.198 & 0.102 & $\mathrm{AX}$ & 0.343 & 0.378 & 0.156 & 0.141 & MBY & 0.173 & 0.509 & 0.304 & 0.033 \\
\hline $\mathrm{XJ}$ & 0.253 & 0.073 & 0.255 & 0.116 & $\mathrm{ZT}$ & 0.179 & 0.306 & 0.116 & 0.168 & SQ & 0.133 & 0.146 & 0.146 & 0.16 \\
\hline ZLJ & 0.237 & 0.047 & 0.143 & 0.121 & ST & 0.179 & 0.556 & 0.399 & 0.139 & GP & 0.121 & 0.167 & 0.145 & 0.154 \\
\hline GJ & 0.22 & 0.077 & 0.133 & 0.092 & $\mathrm{YT}$ & 0.133 & 0.315 & 0.094 & 0.139 & $\mathrm{JL}$ & 0.15 & 0.273 & 0.154 & 0.151 \\
\hline DA & 0.243 & 0.099 & 0.149 & 0.137 & $\mathrm{CS}$ & 0.238 & 0.221 & 0.381 & 0.236 & NB & 0.145 & 0.414 & 0.169 & 0.122 \\
\hline YT & 0.281 & 0.114 & 0.192 & 0.112 & AJ & 0.232 & 0.375 & 0.353 & 0.008 & YS & 0.089 & 0.296 & 0.167 & 0.121 \\
\hline $\mathrm{RX}$ & 0.47 & 0.318 & 0.355 & 0.022 & PX & 0.205 & 0.359 & 0.217 & 0.117 & PA & 0.1 & 0.258 & 0.159 & 0.119 \\
\hline
\end{tabular}




\begin{tabular}{|c|c|c|c|c|}
\hline & $\mathrm{P}$ & $\mathrm{S}$ & $\mathrm{R}$ & $\mathrm{U}$ \\
\hline YL & 0.097 & 0.304 & 0.229 & 0.122 \\
\hline $\mathrm{XC}$ & 0.102 & 0.288 & 0.168 & 0.123 \\
\hline LZ & 0.135 & 0.339 & 0.221 & 0.141 \\
\hline $\operatorname{PS}(1)$ & 0.298 & 0.211 & 0.277 & 0.183 \\
\hline DP & 0.233 & 0.19 & 0.16 & 0.105 \\
\hline QS & 0.217 & 0.136 & 0.187 & 0.152 \\
\hline $\mathrm{RS}$ & 0.61 & 0.251 & 0.384 & 0.104 \\
\hline DL & 0.154 & 0.138 & 0.166 & 0.176 \\
\hline HY & 0.162 & 0.51 & 0.199 & 0.151 \\
\hline $\mathrm{CP}$ & 0.129 & 0.275 & 0.18 & 0.103 \\
\hline $\mathrm{NX}$ & 0.188 & 0.207 & 0.207 & 0.105 \\
\hline YB & 0.115 & 0.549 & 0.248 & 0.114 \\
\hline JA & 0.175 & 0.208 & 0.237 & 0.113 \\
\hline CL & 0.368 & 0.262 & 0.257 & 0.114 \\
\hline GX(1) & 0.134 & 0.305 & 0.224 & 0.112 \\
\hline $\mathrm{GX}(2)$ & 0.160 & 0.269 & 0.191 & 0.109 \\
\hline $\mathrm{JL}$ & 0.178 & 0.369 & 0.657 & 0.103 \\
\hline XW & 0.137 & 0.32 & 0.293 & 0.117 \\
\hline $\operatorname{PS}(2)$ & 0.167 & 0.347 & 0.211 & 0.134 \\
\hline GA & 0.188 & 0.304 & 0.292 & 0.114 \\
\hline QF & 0.419 & 0.204 & 0.185 & 0.107 \\
\hline HK & 0.300 & 0.184 & 0.212 & 0.101 \\
\hline CY & 0.175 & 0.405 & 0.292 & 0.088 \\
\hline WS & 0.209 & 0.337 & 0.246 & 0.098 \\
\hline
\end{tabular}

\begin{tabular}{|c|c|c|c|c|}
\hline & $\mathrm{P}$ & $\mathrm{S}$ & $\mathrm{R}$ & $\mathrm{U}$ \\
\hline LS & 0.186 & 0.457 & 0.266 & 0.114 \\
\hline $\mathrm{TC}$ & 0.27 & 0.217 & 0.058 & 0.094 \\
\hline $\mathrm{DZ}(1)$ & 0.261 & 0.429 & 0.436 & 0.101 \\
\hline XH & 0.28 & 0.799 & 0.471 & 0.092 \\
\hline $\mathrm{KJ}$ & 0.322 & 0.337 & 0.263 & 0.104 \\
\hline $\mathrm{DZ}(2)$ & 0.291 & 0.513 & 0.374 & 0.093 \\
\hline QX & 0.303 & 0.517 & 0.373 & 0.103 \\
\hline $\mathrm{YC}$ & 0.155 & 0.320 & 0.204 & 0.206 \\
\hline MS & 0.332 & 0.227 & 0.17 & 0.137 \\
\hline YJ(1) & 0.188 & 0.429 & 0.255 & 0.13 \\
\hline HY & 0.12 & 0.462 & 0.169 & 0.096 \\
\hline SM & 0.228 & 0.504 & 0.181 & 0.126 \\
\hline LS & 0.142 & 0.345 & 0.21 & 0.102 \\
\hline $\mathrm{YJ}(2)$ & 0.187 & 0.455 & 0.172 & 0.158 \\
\hline JY & 0.144 & 0.537 & 0.375 & 0.115 \\
\hline AY & 0.152 & 0.576 & 0.301 & 0.05 \\
\hline $\mathrm{LZ}$ & 0.126 & 0.429 & 0.178 & 0.159 \\
\hline $\mathrm{YZ}$ & 0.031 & 0.047 & 0.385 & 0.700 \\
\hline WZ & 0.136 & 0.712 & 0.579 & 0.134 \\
\hline QJ & 0.102 & 0.529 & 0.31 & 0.268 \\
\hline FL & 0.188 & 0.662 & 0.576 & 0.397 \\
\hline DDK & 0.169 & 0.055 & 0.25 & 0.217 \\
\hline $\mathrm{JB}$ & 0.122 & 0.081 & 0.666 & 0.25 \\
\hline SPB & 0.078 & 0.087 & 0.514 & 0.342 \\
\hline
\end{tabular}

\begin{tabular}{|c|c|c|c|c|}
\hline & $\mathrm{P}$ & $\mathrm{S}$ & $\mathrm{R}$ & $\mathrm{U}$ \\
\hline JLP & 0.108 & 0.113 & 0.498 & 0.204 \\
\hline NA & 0.107 & 0.086 & 0.573 & 0.202 \\
\hline BB & 0.129 & 0.194 & 0.292 & 0.176 \\
\hline YB & 0.105 & 0.285 & 0.466 & 0.196 \\
\hline $\mathrm{BN}$ & 0.111 & 0.371 & 0.346 & 0.198 \\
\hline $\mathrm{CS}$ & 0.222 & 0.323 & 0.325 & 0.192 \\
\hline $\mathrm{JJ}(3)$ & 0.230 & 0.607 & 0.461 & 0.131 \\
\hline $\mathrm{HC}$ & 0.158 & 0.48 & 0.375 & 0.169 \\
\hline $\mathrm{YC}$ & 0.153 & 0.391 & 0.388 & 0.205 \\
\hline $\mathrm{NC}$ & 0.160 & 0.521 & 0.282 & 0.123 \\
\hline ZJ & 0.203 & 0.468 & 0.368 & 0.136 \\
\hline DZ & 0.157 & 0.389 & 0.364 & 0.167 \\
\hline BS & 0.084 & 0.210 & 0.370 & 0.180 \\
\hline TL & 0.131 & 0.387 & 0.293 & 0.200 \\
\hline $\mathrm{TN}$ & 0.169 & 0.443 & 0.302 & 0.254 \\
\hline $\mathrm{RC}$ & 0.180 & 0.253 & 0.297 & 0.154 \\
\hline LP & 0.131 & 0.404 & 0.290 & 0.161 \\
\hline FD & 0.161 & 0.516 & 0.301 & 0.167 \\
\hline DJ & 0.141 & 0.344 & 0.283 & 0.127 \\
\hline $\mathrm{ZX}$ & 0.137 & 0.475 & 0.303 & 0.095 \\
\hline KX & 0.120 & 0.764 & 0.382 & 0.149 \\
\hline YY & 0.086 & 0.681 & 0.364 & 0.157 \\
\hline
\end{tabular}

